\title{
Urban Soundscape Assessment by Visually Impaired People: First Methodological Approach in Granada (Spain)
}

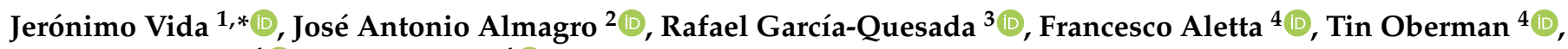 \\ Andrew Mitchell ${ }^{4}$ (I) and Jian Kang ${ }^{4}$ (D) \\ 1 Applied Physics Department, Faculty of Sciences, University of Granada, 18071 Granada, Spain \\ 2 Scientific Instrumentation Center, CITIC, University of Granada, 18071 Granada, Spain; jaalmagro@ugr.es \\ 3 Building Construction Department, School of Architecture, University of Granada, 18071 Granada, Spain; \\ rafaelgq@ugr.es \\ 4 Institute for Environmental Design and Engineering, University College London, London WC1H 0NN, UK; \\ f.aletta@ucl.ac.uk (F.A.); t.oberman@ucl.ac.uk (T.O.); Andrew.mitchell.18@ucl.ac.uk (A.M.); \\ j.kang@ucl.ac.uk (J.K.) \\ * Correspondence: jvida@ugr.es
}

check for updates

Citation: Vida, J.; Almagro, J.A.; García-Quesada, R.; Aletta, F.; Oberman, T.; Mitchell, A.; Kang, J. Urban Soundscape Assessment by Visually Impaired People: First Methodological Approach in Granada (Spain). Sustainability 2021, 13, 13867. https://doi.org/10.3390/ su132413867

Academic Editors: Jooyoung Hong and Bhan Lam

Received: 3 November 2021

Accepted: 12 December 2021

Published: 15 December 2021

Publisher's Note: MDPI stays neutral with regard to jurisdictional claims in published maps and institutional affiliations.

Copyright: (C) 2021 by the authors. Licensee MDPI, Basel, Switzerland. This article is an open access article distributed under the terms and conditions of the Creative Commons Attribution (CC BY) license (https:/ / creativecommons.org/licenses/by/ $4.0 /)$.

\begin{abstract}
Soundscape assessments by citizens are starting to emerge as a common practice, normally carried out in context by means of soundwalks along selected paths with volunteers. However, when such assessments are carried out, either in situ or in laboratory experiments, visually impaired citizens are not usually involved. To address this question, three soundwalks were carried out in 2020 in the city of Granada, in southern Spain, with the participation of visually impaired people. In this paper, we present the lessons learnt from this research with respect to the methodology issues that have to do with soundwalking and the surveying procedures when people with limited vison are participating, the assessment results, and a comparison with a soundscape evaluation carried out in 2019 without the collaboration of visually impaired people. The results of this preliminary campaign highlight that: (1) Adapting soundscape assessment protocols from standards for visually impaired people is a methodological challenge that requires research attention; (2) Some of the different patterns in the assessment of the soundscape pleasantness between visually impaired and nonvisually impaired participants emerged; (3) The perception of quietness may differ for visually impaired people when orientation and identification are factors that play a role in the acoustic environment evaluation.
\end{abstract}

Keywords: environmental noise; soundscape; perception; visually impaired; urban design

\section{Introduction}

In the context of the noise laws and regulations of Europe and the national Member States, environmental urban sounds exceeding legal limits are always interpreted as pollutants; they are just noise, affecting human health, and a source of annoyance for citizens. There is little place for urban soundscapes in national regulations, nor for soundscape protection, nor even for official recommendations for urban landscape design that include the soundscape vision. Soundscape concepts in policy documents, nowadays, are scarce [1], and the participation of citizens in consultation processes is often poor and limited in time.

The above context provides, altogether, a regrettable scenario, in which urban sounds are only analyzed from a decibel point of view as a form of pollution, without the empowerment of general citizens, and without soundscape criteria in urban design. The technical approach has proven to be insufficient to describe all the characteristics and dimensions of the urban acoustic environment [2], the importance of the perceptions of the citizens in context when determining annoyance affection and quality-of-life issues, and the extraordinary value and importance it can gain in achieving the sustainable development goals of the 2030 Agenda and the Green Deal in Europe, as soundscape research over the last ten years has clearly shown [3]. 


\subsection{Urban Design and Sound Perception in Context}

The importance given to preferred urban sounds as a way to improve the quality of life of citizens, or the relevance of certain urban acoustic environments, of high cultural value in their own right, to be preserved and restored if degraded, have changed it all. At present, urban soundscape studies is a research field closely linked to urban sustainable design, resulting in spaces where ambient noise is not the protagonist of the scene because of its magnitude, but as a consequence of the way in which it is perceived, including health-related issues [4-6]. The city of Granada, in southern Spain, is not far from this strategic movement of using soundscape evaluations to complement and accompany legal commitments, meaning that urban acoustic climate research, by means of soundwalks, is not a new discipline. For example, soundscape assessments were carried out in 2018 in some conflictive urban areas as a complementary work to including the vision of citizens in the newly revised city noise action plan that was to be carried out, as demanded by national legislation $[7,8]$.

Soundscape evaluations were also carried out in 2019 within the Soundscape Indices (SSID) project, supplemented with First-Order Ambisonics (FOA) audio recordings, and $4 \mathrm{k} / 360$ video recordings, at some of the most iconic sites of great touristic and heritage value in the city. The urban soundscape was also 4k/360-recorded during the COVID-19 lockdown in Granada in order to characterize the new scenario and increase the realistic audio and video data for future auditions, as well as for comparison purposes [9]. Since 2017, the use of the HUSH City App by citizens, for soundscape and public spaces research, has also been fostered in the city as another way to increase public participation in local noise management and control issues [10]. This research, as well as international cooperation activity, have increased the experience in soundscaping and the knowledge of the local acoustic climate to complement the evaluation tools already implemented in Granada since 2008, as demanded by law.

In this relatively new scenario, the collaboration of people is of fundamental importance, making soundscape perception assessments by citizens a common practice nowadays for a better integration of the noise issues in urban design under sustainable criteria. Soundwalks along selected paths, with volunteers answering a survey at every stop site or, alternatively, surveying people around selected assessment spots, are common in situ methods in soundscape research. If in situ research is not possible, or if it is difficult to develop, the local context can be artificially reproduced in auditions that include both the visual appearance and the acoustic climate of the ambient previously recorded in binaural or FOA audio, together with $4 \mathrm{k} 360$ video quality, for highly accurate reproductions for participants [11]. However, when facing this task, either in situ or by means of laboratory experiments, visually impaired citizens are not commonly involved, a fact that has motivated the design of an innovative and collaborative project involving totally or partially blind people called, "sOuNdsCapE Granada 2020".

\subsection{Inclusive Soundscape Assessments: The Case of Visually Impaired People}

Overall, the literature on how visually impaired people assess urban soundscapes is relatively scarce. Mediastika et al. [12] showed that, besides the common perceptual constructs of pleasantness and eventfulness that are embedded in the soundscape assessment protocols [13], visually impaired people rely on additional soundscape dimensions related to audible safety, directionality, spatiality, and naturality. Similar trends seem to emerge also when the soundscape approach is applied to the assessment of public indoor spaces [14].

To the best of the authors' knowledge, no research on the topic has been conducted in Spain so far. To address this question, which is, in itself, a relevant social research methodology challenge nowadays, and to improve and extend the scope of soundscape assessments of urban acoustic environments by incorporating this collective's perception, three soundwalks were carried out within the "sOuNdsCapE Granada 2020" project with the participation of visually impaired people. These soundwalks were designed by tak- 
ing into consideration, not only common questions in soundscape research by means of soundwalks, but also the advice given by ONCE, the national organization for the blind in Spain.

The purposes of this research are to provide visually impaired people the opportunity to collaborate in soundscape research, and to learn from their perceptions and interpretations of the urban acoustic environment. This is a socially inclusive project that complements the results from traditional soundscape evaluations with people without visual limitations, and that investigates what is it like soundwalking with people with limited vision, what changes have to be made to the traditional methodology when this collective is involved, and determines new opportunities for research from the added value and perspectives provided by their answers, which take into account the social issues and dimensions that are hard to guess from surveys when normally sighted people are included in the sample of participants.

\subsection{A First Methodological Approach}

Therefore, to summarize, the first aim of this paper is to explore appropriate methods for soundscape evaluations for visually impaired people. The second aim is to present their evaluations of urban acoustic environments. Finally, a third aim of this paper is to investigate how different the soundscape evaluations are from normally sighted people with respect to the interpretations of people with limited vision. Second and third research questions, addressed as a first approximation, pending new experiences, would benefit from the present first approach.

In this paper, the lessons learnt from this innovative and collaborative research are presented together with the first analysis and assessment results. A comparison with perception data acquired in 2019 , at a coincident soundscape evaluation site, with normally sighted people, is also included as a case study. The most challenging task in 2020 was the method, which had to be adapted from one soundwalk to the next one in an attempt to maximize the survey work and the overall quality of the responses to a questionnaire that, as in 2019, followed the ISO 12913 recommendations [13,15]. The results from this research also provide some insights into a deeper soundscape-related question arising nowadays, which is whether the soundscape data collection tools are inclusive enough, i.e., whether they take into account the needs of other communities (the visually impaired community in this case).

\section{Methodological Protocol Revision}

As mentioned before, visually impaired people rarely participate in urban soundscape evaluations around the world, and have never done so in the city of Granada. This motivated the design of the "sOuNdsCapE Granada 2020" project, a research initiative involving totally or partially blind people who received the endorsement, help, and collaboration of all the institutions consulted, as explained below.

\subsection{Agreement with ONCE and Project Outline}

The project began to take shape in early 2020, when initial contacts were established with the ONCE delegation in Granada (ONCE stands for Organización Nacional de Ciegos Españoles, the Spanish national organization for the blind). The project outline, based on the realization of soundwalks, was well-received by ONCE, but was seen from the outset as a major organizational challenge. The COVID-19 lockdown stopped the initiative for some time, until July 2020, when contacts resumed, this time with the collaboration and support of the Granada City Council. The project outline was then approved, the main purpose being to preserve and evaluate city sounds as a resource and, as a second derivative, to fight against noise pollution as a source of bewilderment and discomfort, which gives rise to confusion among the members of the ONCE collective. Participants were selected by ONCE from a call for volunteers in good health conditions for an approximately 2-km-long walk, and the questionnaire was to be adapted by the UGR research team to an online 
platform that visually impaired people could listen to along the path. Listening to their mobile devices is a common practice by ONCE affiliates in their everyday living.

By the time the initiative was officially communicated and launched, on the 7 September 2020, the project had public support and encouragement from not only ONCE and the City Council, but also from the Spanish Acoustic Society (SEA) and the CONAMA Foundation [16]. Colleagues from the UCL (SSID) assisted the UGR research team in the layout first stage of the project development, and valuable suggestions and comments from SEA and CONAMA also helped in this task. Finally, the sound level meter and the $4 \mathrm{k} / 360$ video and FOA recording equipment, from the Anechoic Chamber at UGR, were used at no cost, enhancing the project value in the context of social responsibility. Figure 1 graphically summarizes this process.

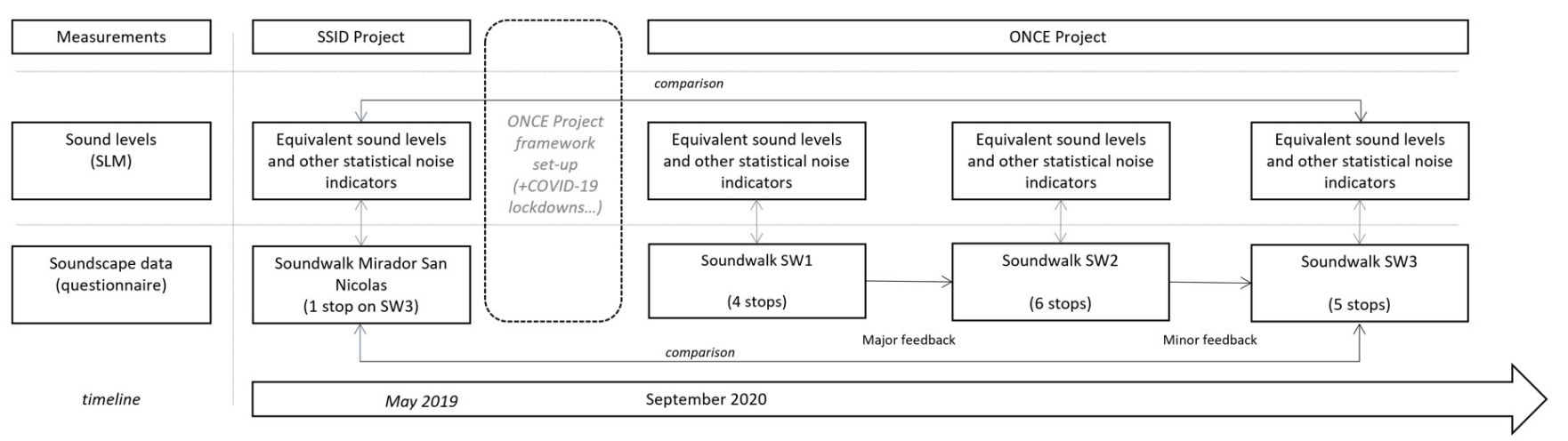

Figure 1. Research-stage synthesis as timeline flowchart.

\subsection{Description of Soundwalk Paths}

Five soundwalks were initially designed, although only three have been carried out to date, whose main characteristics are depicted in Table 1. It was thought that two paths along the city center, with no steep roads and no difficulty in walking, would help participants become accustomed to what a soundwalk is and how to proceed. It was also thought that any inconvenience or problem that would arise from a technical point of view (4k/360 audio/video recordings) would also be easily solved. After these first two paths, three more soundwalks were designed along the Albaicín Moorish district, where steep and narrow roads are frequently together with steps and, occasionally, stone asphalt, which could complicate the experience for visually impaired people and their accompanying assistants. As stated above, only three soundwalks have been completed up to now.

Table 1. Soundwalks with ONCE affiliates: main characteristics.

\begin{tabular}{cccccc}
\hline Soundwalk & Urban Typology & Code & Length $\mathbf{( k m )}$ & Stops & Date \\
\hline SW1 & City centre & URB_1 & 1.4 & $8\left(^{*}\right)$ & 17 September 2020 \\
SW2 & City centre & URB_2 & 1.1 & 6 & 22 September 2020 \\
SW3 & Albaicín Moorish district & ALB_1 & 0.8 & $6\left(^{*}\right)$ & 25 September 2020 \\
\hline
\end{tabular}

$\left.{ }^{*}\right)$ the 8 planned stops during SW1 resulted in only 4 effective stops when performing the experience; similarly, 6 planned stops during SW3 resulted in only 5 when performed.

A pictorial view of the soundwalk stop sites can be seen in Figures 2-4 for, respectively, the first soundwalk (SW1), the second soundwalk (SW2), and the third soundwalk (SW3). Two views at each stop site are shown in Figure 2 for SW1, in Figure 3 for SW2, and in Figure 4 for SW3. Detailed path descriptions are shown, respectively, in Figures 5-7, together with a global view of the three soundwalk routes in Figure 8. The strategic noise map of the city shows a color map of the sound levels along the streets in these figures (follow this link for daytime information: https://sicaweb.cedex.es/docs/mapas/fase3/aglomeracion/ GRANADA/Ag_AND_GRANADA_C_Ld.pdf), (accessed on 10 December 2021). 

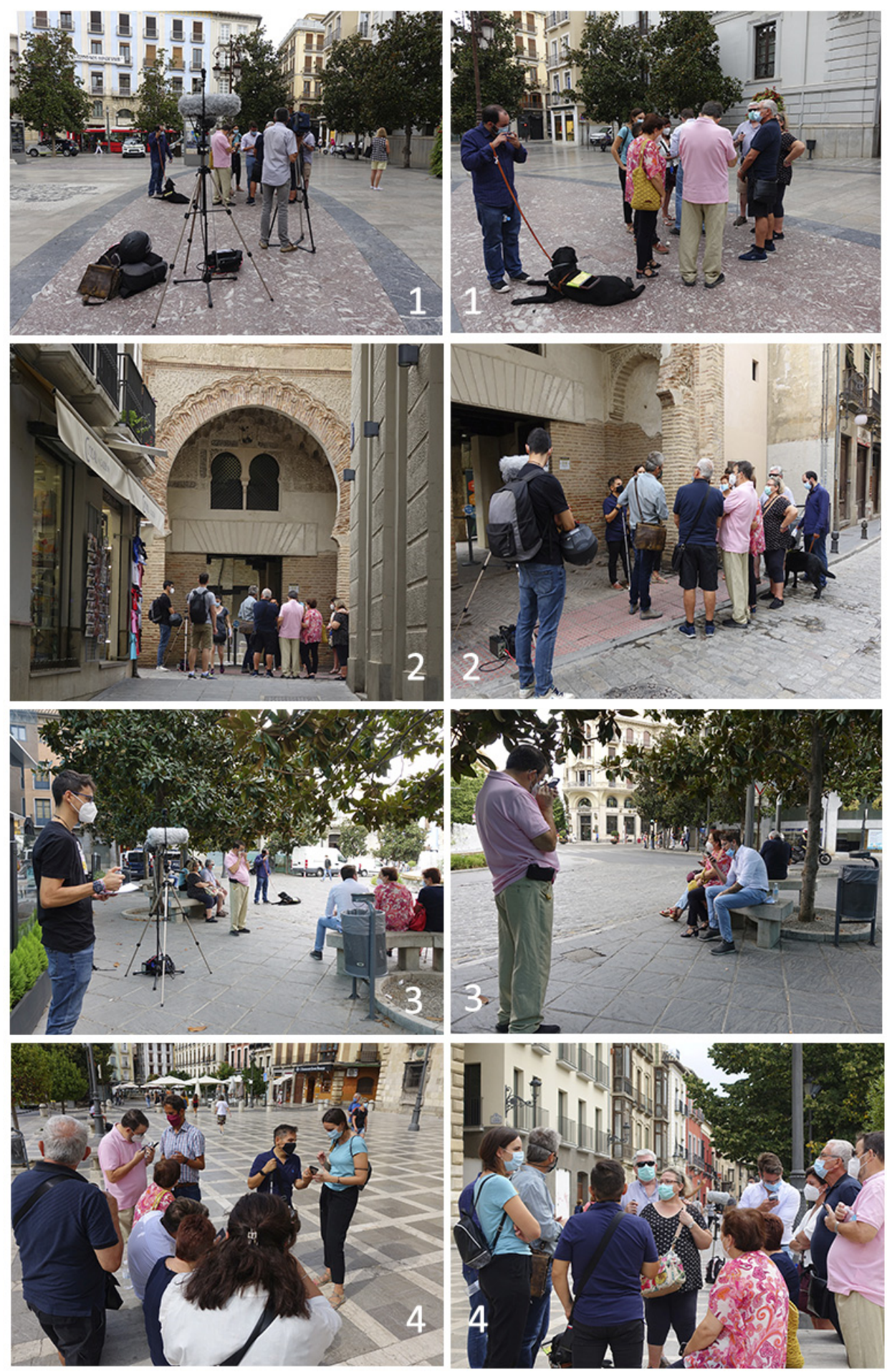

Figure 2. Photographic tour of evaluation sites during the first soundwalk (SW1). Double views for each stop site: from top to bottom, Stop Sites 1, 2,3, and 4. 

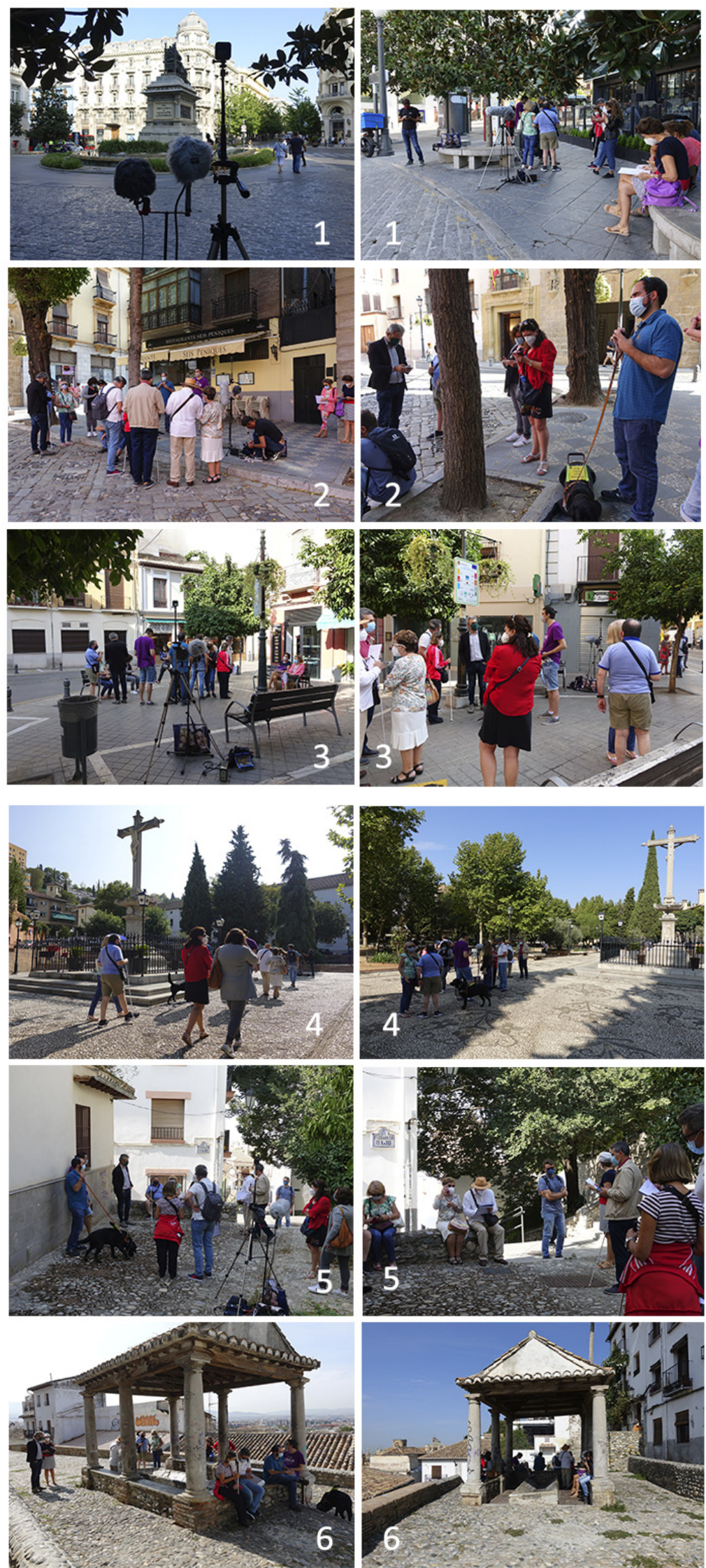

Figure 3. Photographic tour of evaluation sites during the second soundwalk (SW2). Double views for each stop site: from top to bottom, Stop Sites 1, 2, 3, 4, 5, and 6. 


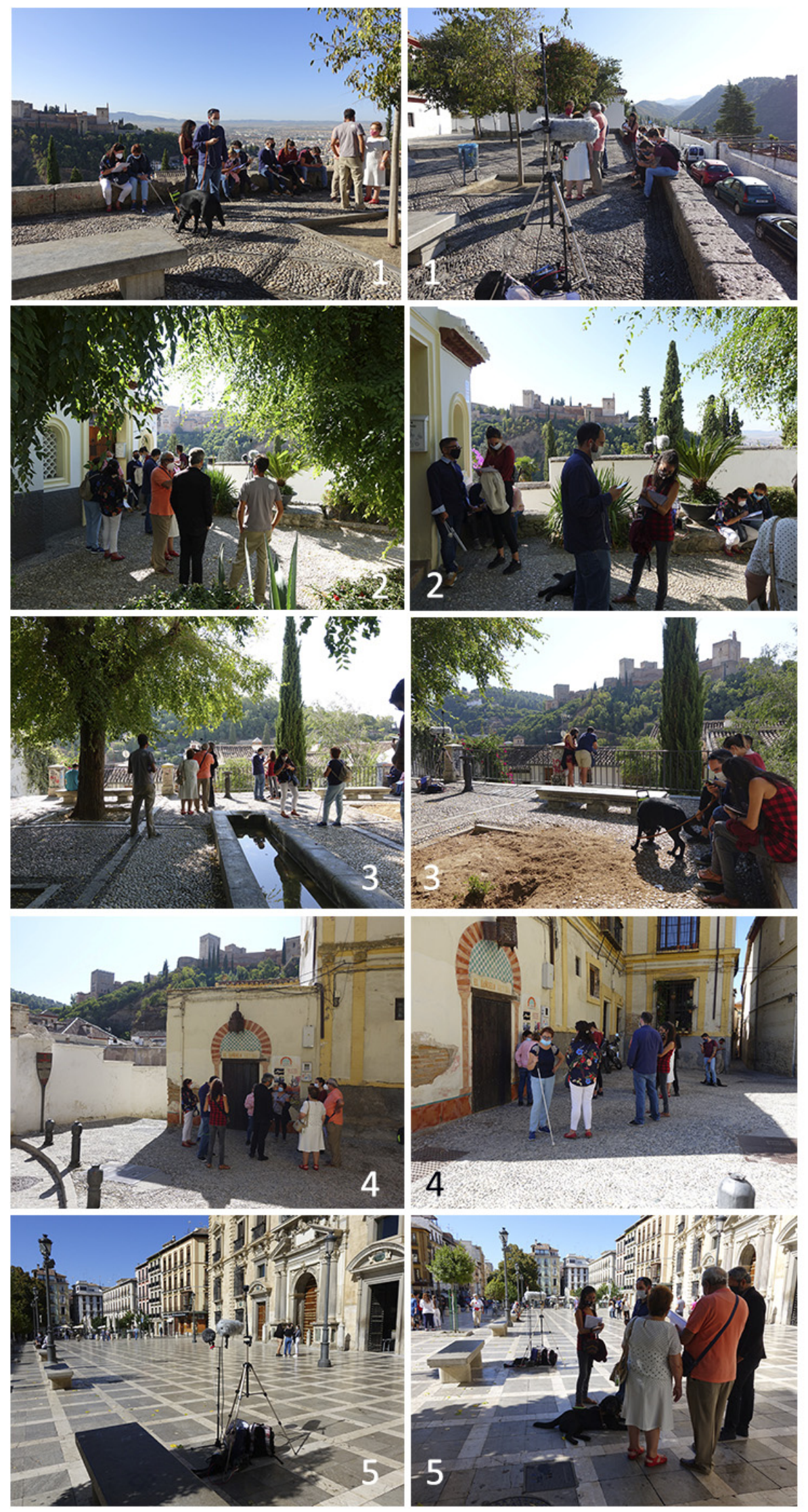

Figure 4. Photographic tour of evaluation sites during the third soundwalk (SW3). Double views for each stop site: from top to bottom, Stop Sites 1, 2, 3, 4, and 5. 


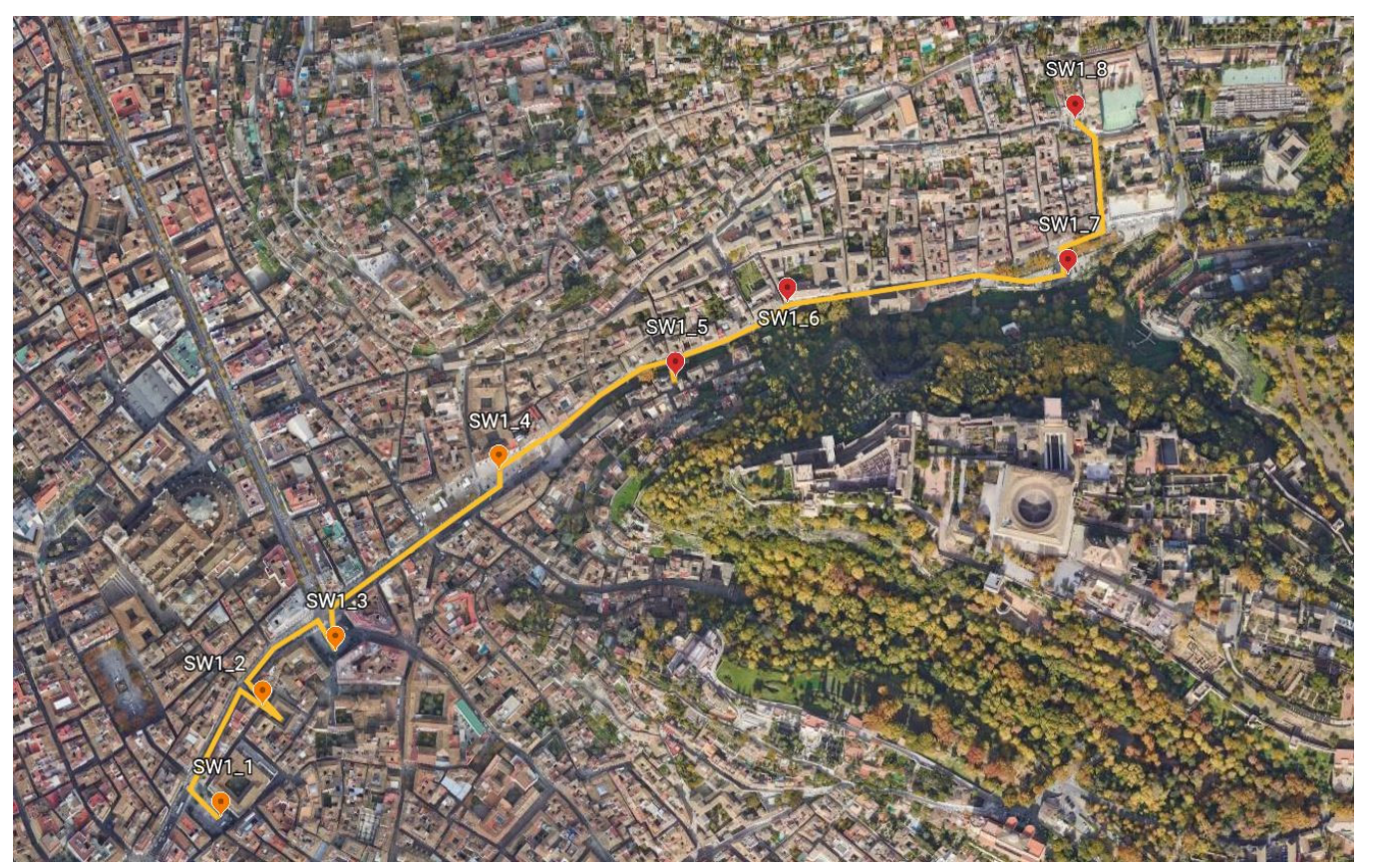

Figure 5. First soundwalk (SW1) path description on the street map of Granada. The Alhambra is clearly seen in the centre right of the image.

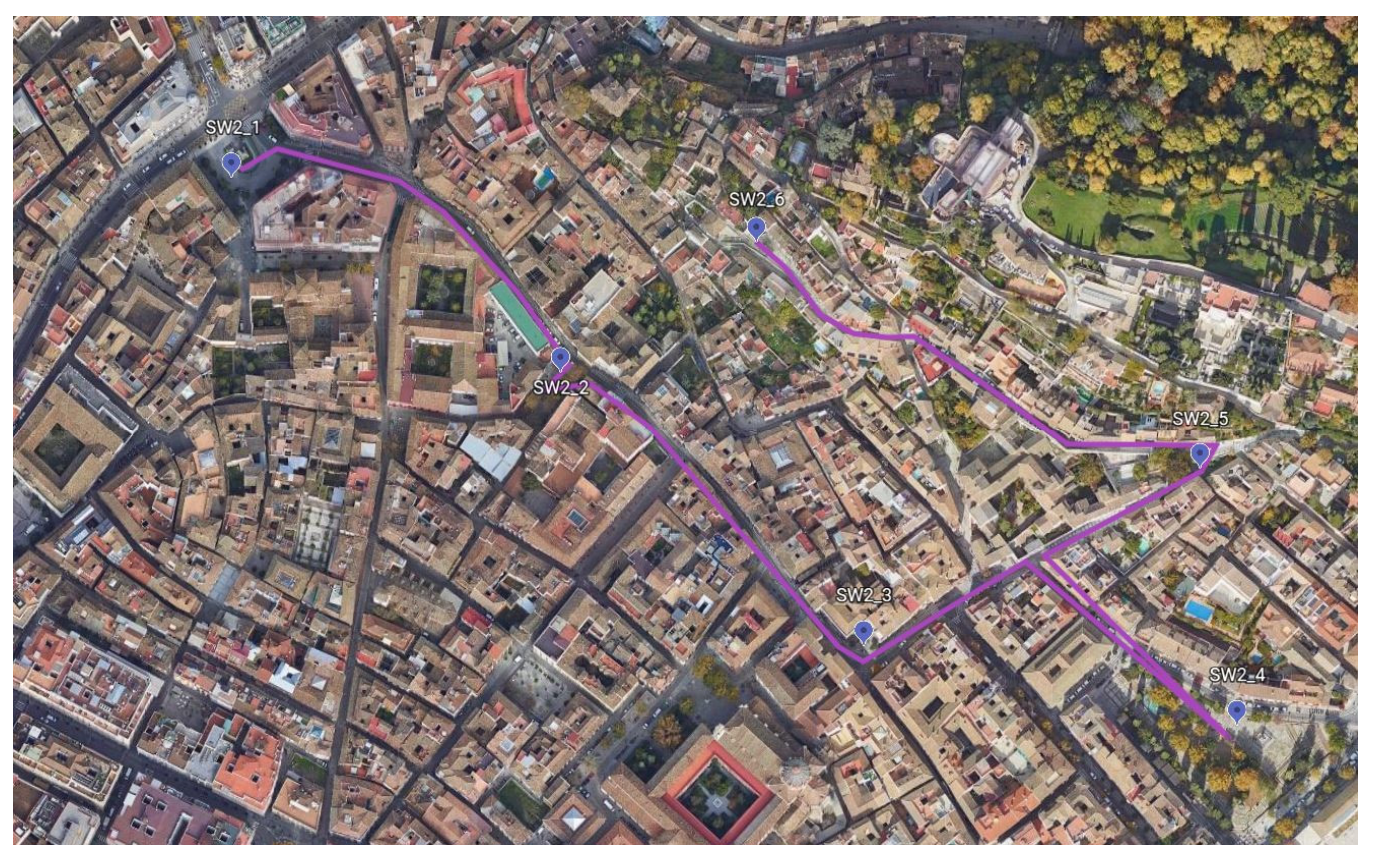

Figure 6. Second soundwalk (SW2) path description on the street map of Granada. SW2_1 stop is the same as SW1_3 in Figure 4. 


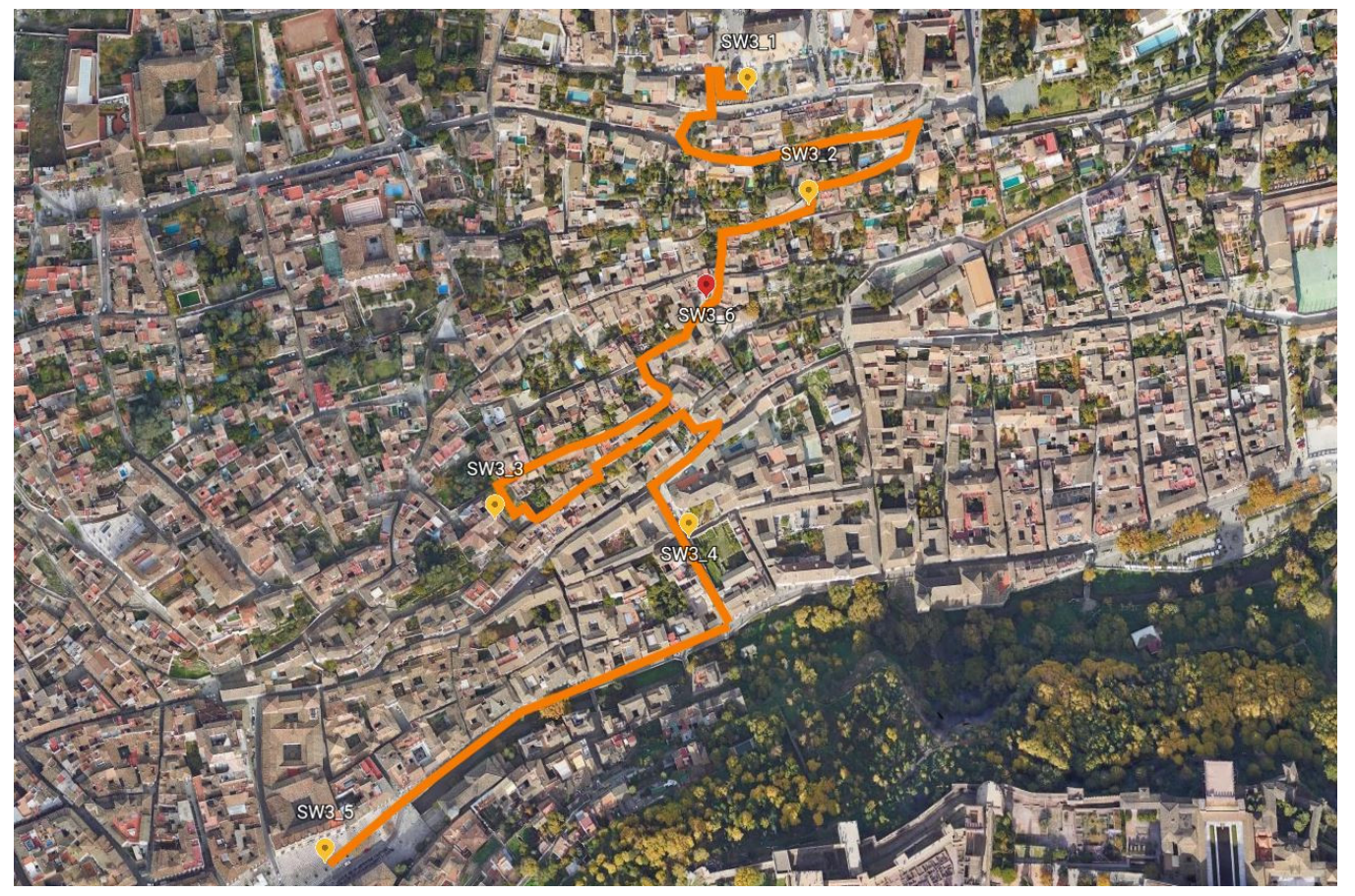

Figure 7. Third soundwalk (SW3) path description on the street map of Granada. SW3_5 stop is the same as SW1_4 in Figure 4.

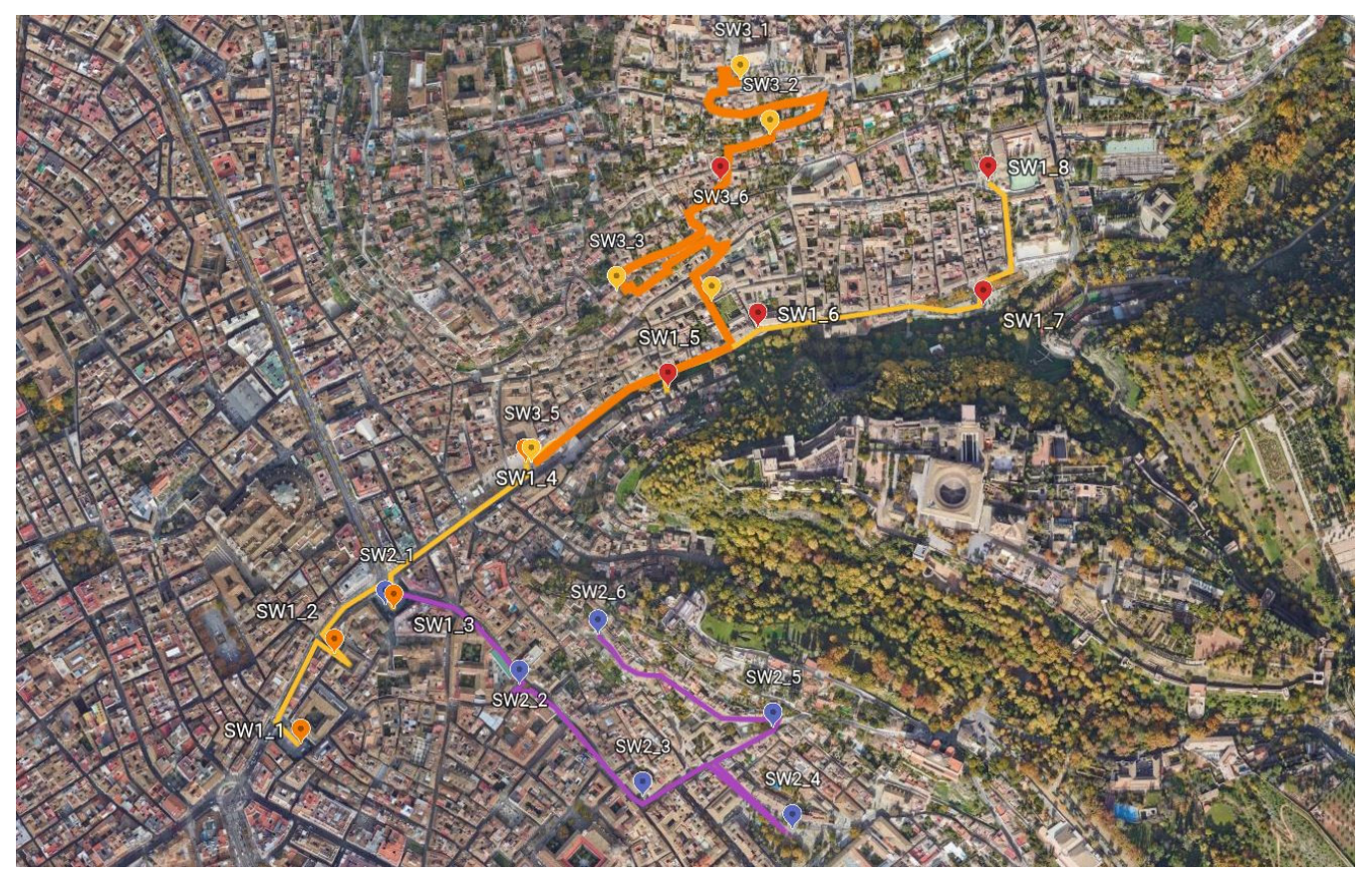

Figure 8. The three soundwalk paths on the street map of Granada.

\subsection{Soundwalks Procedure}

The main characteristics of the soundwalk and the procedure methodology were explained to the participants at the beginning of each walk at the departing site, in a street meeting that took around half an hour. The explanations from the research team to the participants always pointed out the answers to five main questions: (i) The path should be walked in silence, with concentration focused on the surroundings sounds; (ii) Once at the evaluation site, the participants should stay 5 to $8 \mathrm{~min}$ in silence, trying to identify the main sound sources and the feelings that these sounds generate; (iii) The 
participants should answer the questionnaire without haste and without meditating on the answers; (iv) Participants should answer all of the items, without leaving empty questions; (v) Once finished, participants should proceed by walking to the next evaluation site and perform the same steps again. The participants were also informed that, while they were doing the evaluation, the research team would be involved in the audio/video recordings, photographing details of the scenario, registering sound levels, and taking notes for later analysis and as a further reference of the incidences. As this task implied the use of heavy and delicate instrumentation, which had to be transported, set up, and the correct functioning revised from one place to another, the participants were advised to not be in a hurry so that there would be enough time between stop sites to do so. As the participants terminated their evaluations, and before proceeding to the next site, a member of the UGR research team, an expert in Granada urbanism and historical data, would share with them stories, anecdotes, and facts, which turned the walk into an authentic tourist tour around the city, with historical nuances of great interest. This extra activity, not initially planned, stoked the interest of the participants who were really impressed during the first soundwalk, and who demanded it afterwards in the following soundwalks.

\subsection{Soundwalk Questionnaires: Online and Paper Versions}

As stated above, the plan was to follow a similar procedure in the soundwalks with the ONCE affiliates as in previous experiences with nonvisually impaired people. To this end, it was decided that the Spanish version of the same questionnaire as that from the SSID evaluations in Granada would be used, a harmonized questionnaire following ISO 12913-2:2018 recommendations that would allow our results to be compared against similar research elsewhere in the world. Further details on the SSID questionnaire can be found in Ref. [11]. The main concern was how to distribute the questionnaire within this collective so that the participants could perform nicely and in comfort. The authors' meetings with ONCE made it clear that performing surveys with totally or partially visually impaired people could only be accomplished in two ways: (i) With the aid of an accompanying assistant person without visual impairment; or (ii) With the aid of the new technologies in the form of an electronic assistant in their mobile devices. The participants' selection was left to the full responsibility and competence of ONCE, who, under their own criteria, decided on the group composition, consisting of visionless people assisted by a dog, or by a nonimpaired person, and limited vision affiliates walking on their own or assisted by a nonimpaired companion. As the ONCE affiliates are accustomed to electronic mobile devices assisting their everyday life, it was thought that the online version of the questionnaire would simplify the survey process, as these devices would dictate the questions and guide them through the process. Full information on the questionnaire's contents is provided in the following paragraph, and Table 2 summarizes the questionnaire versions used in the soundwalks.

Table 2. Versions of the soundwalk questionnaire including hosting system and number of questions.

\begin{tabular}{cccc}
\hline Soundwalk & Version & Online Hosting & Number of Questions \\
\hline SW1 & Online & Qualtrix & 12 \\
SW2 & Online and paper booklet & Google & 15 \\
SW3 & Online and paper booklet & Google & 16 \\
\hline
\end{tabular}

\subsection{Description of Soundwalk Questionnaire}

The questionnaire for collecting data on how people perceived the acoustic environment during SW1 combines queries from the ISO 12913-2:2018 Method A and Method B, the SSID protocol [11], as well as some additional questions considered to be adequate from previous experiences [7,8]. Composed in Qualtrix (https://www.qualtrics.com/es/cuentagratuita/, (accessed on 10 December 2021)) and distributed online among the ONCE affiliates, a detailed description of SW1 is provided in Table 3, and the survey structure is as follows: 
- A welcome message and information on what it is all about;

- Informed consent to go ahead and fill out the survey;

- Evaluation site (stop number) selection;

- 12 specific questions for soundscape evaluation.

Table 3. Detailed description of SW1 questionnaire, including correspondence with the SSID project and the ISO standard. For full questionnaire (both Spanish version and English translation), please see Supplementary Materials.

\begin{tabular}{|c|c|c|c|c|}
\hline Question & Content & SSID & & ISO 12913-2:2018 \\
\hline Q1 & Sound source dominance & Yes & Yes & Method A \\
\hline Q2 & Soundscape perceptual attributes & Yes & Yes & Method A \\
\hline Q3 & Overall assessment of sound environment & Yes & Yes & Method A \\
\hline Q4 & Appropriateness of sound environment & Yes & Yes & Method A \\
\hline Q5 & How calm is it here? & No & No & \\
\hline Q6 & How pleasant is it here? & No & No & (Opposite question is in Method B) \\
\hline Q7 & How loud is it here? (volume, not quality) & Yes & Yes & Method B \\
\hline Q8 & How often do you visit this place? & Yes & No & (Similar question is found in Method B) \\
\hline Q9 & Gender & Yes & No & \\
\hline Q10 & Occupational status & Yes & No & (Similar question is found in Method C) \\
\hline Q11 & Level of education & Yes & No & \\
\hline Q12 & WHO-5 items & Yes & No & \\
\hline
\end{tabular}

A detailed description of the questions can be found in the ISO 12913 standard and in the Supplementary Materials, as shown in the last column of Table 3. Question Q5, not included in the ISO, was answered on a five-item scale, as follows: 1 = not at all; 2 = slightly; 3 = moderately; 4 = very; 5 = perfectly (see Supplementary Material).

The questionnaire used in SW2 was a revised version of a previous survey, modified as explained below. Composed in Google Form (https:/ /www.google.es/intl/es/forms/ about/, (accessed on 10 December 2021)) and distributed online and as a paper booklet, the survey structure followed a similar patter as in SW1, but included one more question, making a total of 13 .

Because of some methodological problems experienced during SW1, the second soundwalk was used to test some changes introduced in the questionnaire to make it easier for visually impaired people to fill it in. To this end, previous questions, Q5 and Q6, were withdrawn from the survey and some questions, identified from $\mathrm{A}$ to $\mathrm{D}$, corresponding to previous questions, Q9 to Q12, were made only once, at Stop Site 1. After that, nine more questions were formulated at every stop site. Out of them, six came from a previous survey, and three were newly formulated, attending recommendations from the ONCE affiliates. A detailed description is provided in Table 4.

Finally, the questionnaire used in SW3 was essentially the same as per SW2, with the addition of another new question, as requested by ONCE, making a total of 14 . As before, the SW3 questionnaire was composed in Google Form and distributed online and as a paper booklet. The new question, which would appear as Question 10, reads as described in Table 5. The questionnaires in Spanish (and their English translations) are reported in the Supplementary Materials. 
Table 4. Detailed description of SW2 questionnaire.

\begin{tabular}{ccc}
\hline Question & Content & Origin \\
\hline A & Q9 & as in SW1 \\
B & Q10 & as in SW1 \\
as in SW1 & as in SW1 \\
D & Q11 & as in SW1 \\
1 & Q8 & as in SW1 \\
2 & Q1 & as in SW1 \\
3 & Q2 & as in SW1 \\
4 & Q3 & as in SW1 \\
5 & Q4 & as in SW1 \\
\hline 7 & Q7 & NEW (Q7N) \\
\hline 8 & To what extent are you able to orientate yourself in this site? & NEW (Q8N) \\
\hline 9 & Would you say environmental noise could be a problem at this site? & NEW (Q9N) \\
\hline
\end{tabular}

Table 5. Description of SW3 Question 10.

\begin{tabular}{ccc}
\hline Question & Content & Origin \\
\hline \multirow{2}{*}{10} & $\begin{array}{c}\text { In relation to pedestrian accessibility, comfort, and architectural barriers that would } \\
\text { prevent access, what was the soundwalk like until you reached the site number? } \\
\text { (a reference to every stop site follows) }\end{array}$ & NEW (Q10N) \\
\hline
\end{tabular}

\section{Results}

This section is organized into two subsections: the first reports on the results of the 2020 soundwalk with visually impaired participants; the second utilizes a subset of the 2020 data for the site of Mirador San Nicolas, and compares it with a dataset from a 2019 campaign at the same site with nonvisually impaired participants.

\subsection{Soundwalk Results in 2020 with Visually Impaired Participants}

\subsubsection{Dataset Description}

Nine participants, three women (F) and six men (M), all visually impaired, took part in SW1, starting at Stop 1. However, their collaboration was irregular (not every participant filled in the survey at every stop) because of different doings that arose just as the soundwalk was running. The collaboration of this group in the soundwalk was irregular, as unforeseen "first-time" problems appeared. These problems had to do with the questionnaire and the electronic assistants, not really well-tuned, and with too many procedural doubts at a time from participants, which overwhelmed the research group. Because of this, not every participant answered every question at every stop on the soundwalk. Additionally, even though eight stops were initially planned, only four were completed as explained before, resulting in a total of 34 questionnaires answered (34 out of $36-9 \times 4$-ideal maximum number of responses). As the SW1 survey contained 12 questions, 408 pieces of info $-34 \times 12$ - conform to the SW1 dataset considering the four stops.

A better response rate was obtained during SW2, after the different issues that appeared during SW1 were resolved, and, again, during SW3, resulting in a total of 67 and 50 questionnaires answered, respectively. Following a similar figure explanation as in SW1, full details of the participants and the dataset descriptions for SW2 and SW3 are provided in Table 6.

A total of 151 questionnaires are included in the dataset, as a result of the three soundwalks carried out to date. These questionnaires include 12, 13, or 14 questions each, depending on the soundwalk (see Table 6), totaling 1.979 pieces of information. 
Table 6. “sOuNdsCapE Granada 2020” project dataset description. ( $\mathrm{N}^{\circ}$ stands for number).

\begin{tabular}{cccccc}
\hline Soundwalk & $\begin{array}{c}\text { Participants Total } \\
\text { (F/M) }\end{array}$ & Stops & $\begin{array}{c}\text { Answers } \\
\text { (Max. Resp. Number) }\end{array}$ & $\begin{array}{c}\mathbf{N}^{\circ} \text { of Questions } \\
\text { in Survey }\end{array}$ & $\begin{array}{c}\text { Pieces of Info } \\
\text { from Soundwalk }\end{array}$ \\
\hline SW1 & $9(3 / 6)$ & 4 & $34(36)$ & 12 & 408 \\
SW2 & $13(6 / 7)$ & 6 & $67(78)$ & 13 & 871 \\
SW3 & $11(7 / 4)$ & 5 & $50(55)$ & 14 & 700 \\
TOTAL & 33 & 15 & $151(169)$ & - & 1.979 \\
\hline
\end{tabular}

\subsubsection{Acoustic Environment Description}

Environmental noise descriptors were derived from measurements made with a RION NL-52EX class 1 sound level meter (see specifications in https:/ / rion-sv.com/products/ NL-52_42-E.html, (accessed on 10 December 2021)). The sound-level data consisted of onesecond time weighting, slow (S) recordings leading to frequency weighting, $\mathrm{A}(\mathrm{dBA})$, and coincident $C(\mathrm{dBC})$ with one-second equivalent $\left(\mathrm{L}_{\mathrm{eq}, 1 \mathrm{~s}}\right)$ measurements during a period $(\mathrm{T})$ of $10 \mathrm{~min}$ at each stop site. From these measurements, the maximum and minimum levels, $\mathrm{L}_{\mathrm{Amax}}$ and $\mathrm{L}_{\mathrm{Amin}}$, as well as the $\mathrm{L}_{10}, \mathrm{~L}_{50}$, and $\mathrm{L}_{90}$ percentile levels and the equivalent sound levels for the period, $\mathrm{L}_{\mathrm{ASeq}, \mathrm{T}}$, were computed for the environmental noise characterization. The results are shown in Table 7.

Table 7. Environmental noise descriptors in dBA for each soundwalk. Note: stop sites marked $\left(^{*}\right)$ are the same place; similarly, stop sites marked $(* *)$ are the same place.

\begin{tabular}{|c|c|c|c|c|c|c|c|c|c|}
\hline Soundwalk & Stop Site & Time (hh:mm) & $\mathbf{L}_{\text {ASeq }}$ & $\mathbf{L}_{\text {Amax }}$ & $\mathrm{L}_{\mathrm{Amin}}$ & $\mathbf{L}_{10}$ & $\mathbf{L}_{50}$ & $\mathrm{~L}_{90}$ & $\left(\mathrm{~L}_{10}-\mathrm{L}_{90}\right)$ \\
\hline \multirow{4}{*}{ SW1 } & 1 & $8: 55$ & 63.4 & 70.2 & 54.0 & 68.3 & 60.8 & 55.2 & 13.1 \\
\hline & 2 & 11:07 & 62.9 & 68.4 & 57.6 & 65.9 & 61.8 & 58.6 & 7.3 \\
\hline & $* 3$ & $11: 41$ & 70.6 & 72.7 & 69.1 & 71.6 & 70.5 & 69.6 & 2.0 \\
\hline & $* * 4$ & $12: 15$ & 60.8 & 74.0 & 52.9 & 62.3 & 56.4 & 54.4 & 7.9 \\
\hline \multirow{6}{*}{ SW2 } & $* 1$ & $10: 24$ & 65.6 & 68.7 & 60.4 & 68.4 & 65.6 & 61.2 & 7.2 \\
\hline & 2 & $11: 06$ & 66.2 & 70.7 & 61.7 & 69.1 & 65.5 & 62.1 & 7.0 \\
\hline & 3 & $11: 03$ & 67.5 & 81.2 & 58.6 & 68.0 & 61.6 & 58.7 & 9.3 \\
\hline & 4 & $11: 25$ & 54.5 & 58.8 & 50.4 & 56.9 & 54.2 & 51.8 & 5.1 \\
\hline & 5 & $11: 48$ & 50.5 & 54.3 & 44.9 & 53.3 & 49.9 & 46.0 & 7.3 \\
\hline & 6 & $12: 13$ & 55.7 & 67.4 & 40.6 & 60.1 & 47.7 & 41.3 & 18.8 \\
\hline \multirow{5}{*}{ SW3 } & 1 & $10: 28$ & 50.5 & 54.7 & 45.2 & 52.8 & 50.5 & 46.5 & 6.3 \\
\hline & 2 & $11: 00$ & 55.4 & 61.1 & 48.6 & 58.5 & 53.9 & 50.6 & 7.9 \\
\hline & 3 & $11: 24$ & 53.0 & 63.0 & 45.7 & 55.4 & 50.2 & 46.9 & 8.5 \\
\hline & 4 & $11: 51$ & 60.0 & 70.0 & 48.1 & 64.7 & 54.4 & 49.9 & 14.8 \\
\hline & $* * 5$ & $12: 15$ & 61.0 & 67.1 & 55.3 & 64.0 & 59.4 & 57.2 & 6.8 \\
\hline
\end{tabular}

Stop Site 3 during the first soundwalk is the same as Stop Site 1 during the second soundwalk (both marked with * in Table 7, see Figures 5 and 6). This site is dominated by a big fountain, which had water moving during the first soundwalk, but which was dry during the second soundwalk, making it a big environmental change. Similarly, Stop Site 4, during the first soundwalk, is the same as Stop Site 5 during the third soundwalk (both marked with ** in Table 7, see Figures 5 and 7), being, in both cases, similar acoustic environments in which people moving around was the main source of noise. The time of day was similar in both site coincidences.

Most of these stop sites are in urban areas, typified as "Residential" or "Touristic" in the acoustic zoning of the city, and the noise descriptors are presented in Figures 9-11, together with the acoustic quality objectives (AQO) for these areas, set to, respectively, $65 \mathrm{dBA}$ (Residential) and $70 \mathrm{dBA}$ (Touristic). The effect of the water falling in the fountain located at Site 3 during SW1 can be easily observed in Figure 9, compared to the situation at Site 1 during SW2 in Figure 10. The difference in the ambient noise maximum levels at Site 4 during SW1 are also noticeable, and are coincident with Site 5 during SW3, though they share similar $\mathrm{L}_{\mathrm{ASeq}}$. 


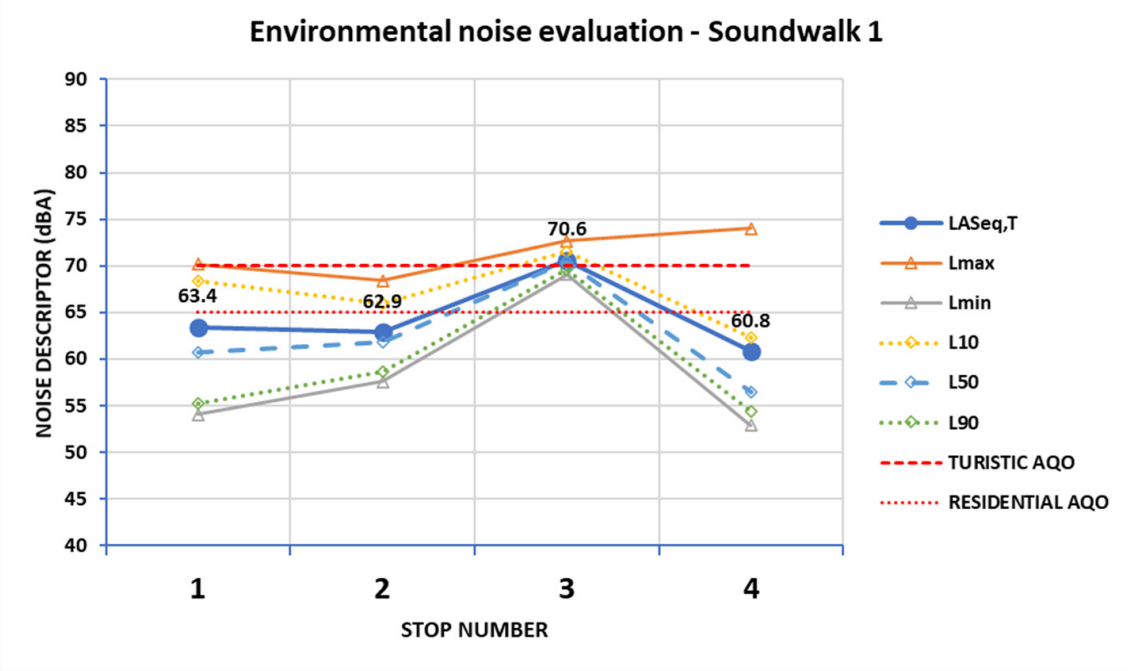

Figure 9. Environmental noise descriptors for Soundwalk 1 (SW1).

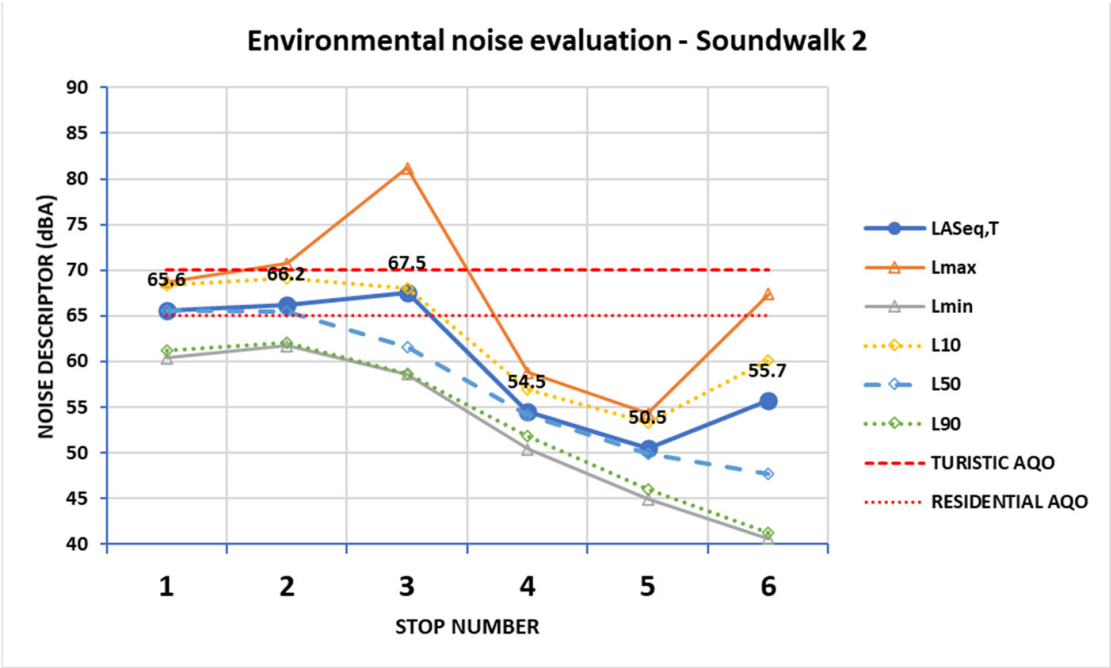

Figure 10. Environmental noise descriptors for Soundwalk 2 (SW2).

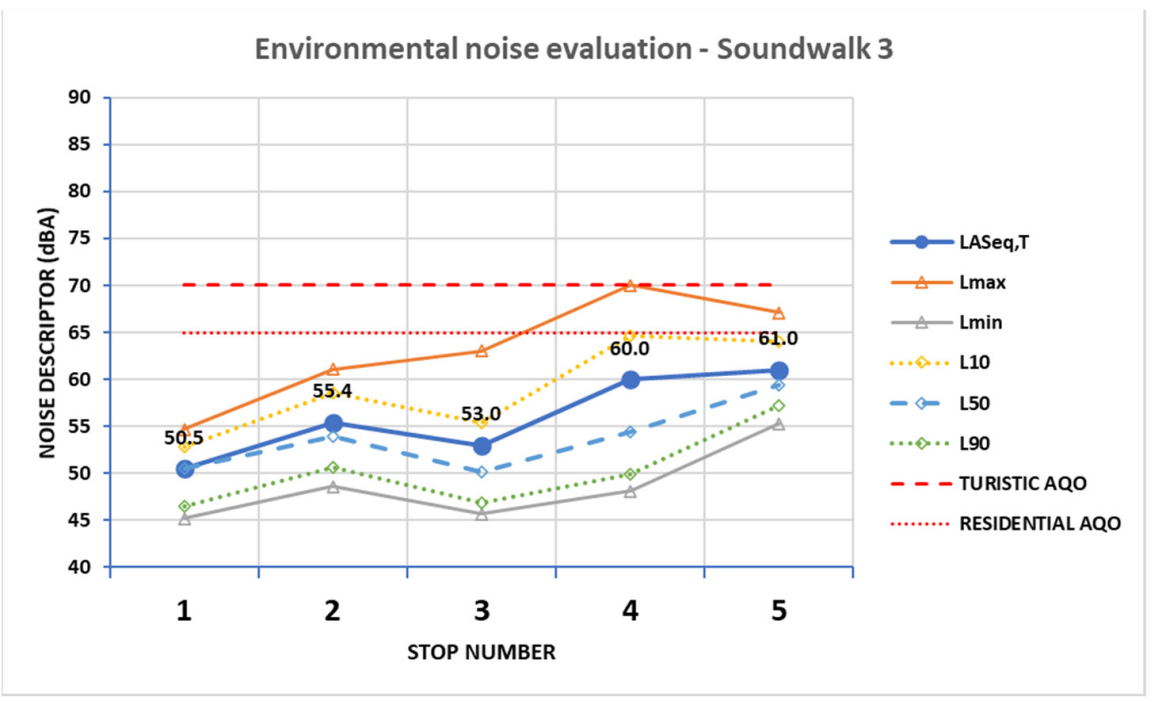

Figure 11. Environmental noise descriptors for Soundwalk 3 (SW3). 


\subsubsection{Sound Source Identification}

Sound source identification was the objective of Q1: "To what extent do you presently hear the following four types of sounds?", which included traffic, sounds of persons, natural sounds, and other noise sources in the evaluation. Figures 12-14 show the mean Q1 answers, together with the equivalent levels and the standard deviations $(\sigma)$ as error bars.

\subsubsection{Perceived Affective Quality (Q2)}

A perceived affective quality assessment was the objective of Question 2 in the survey. This is the main question concerning the citizens' perceptions of the urban acoustic environments, and the Soundscape Attributes Translation Project (SATP) [17], a proposed translation into Spanish of the ISO perception model components [18], was used in the evaluation. Mean answers are also characterized by great $\sigma$ values, as shown in Figures 15-17. Figure 18 shows these findings according to the ISO 12913-3 preferred representation [19].

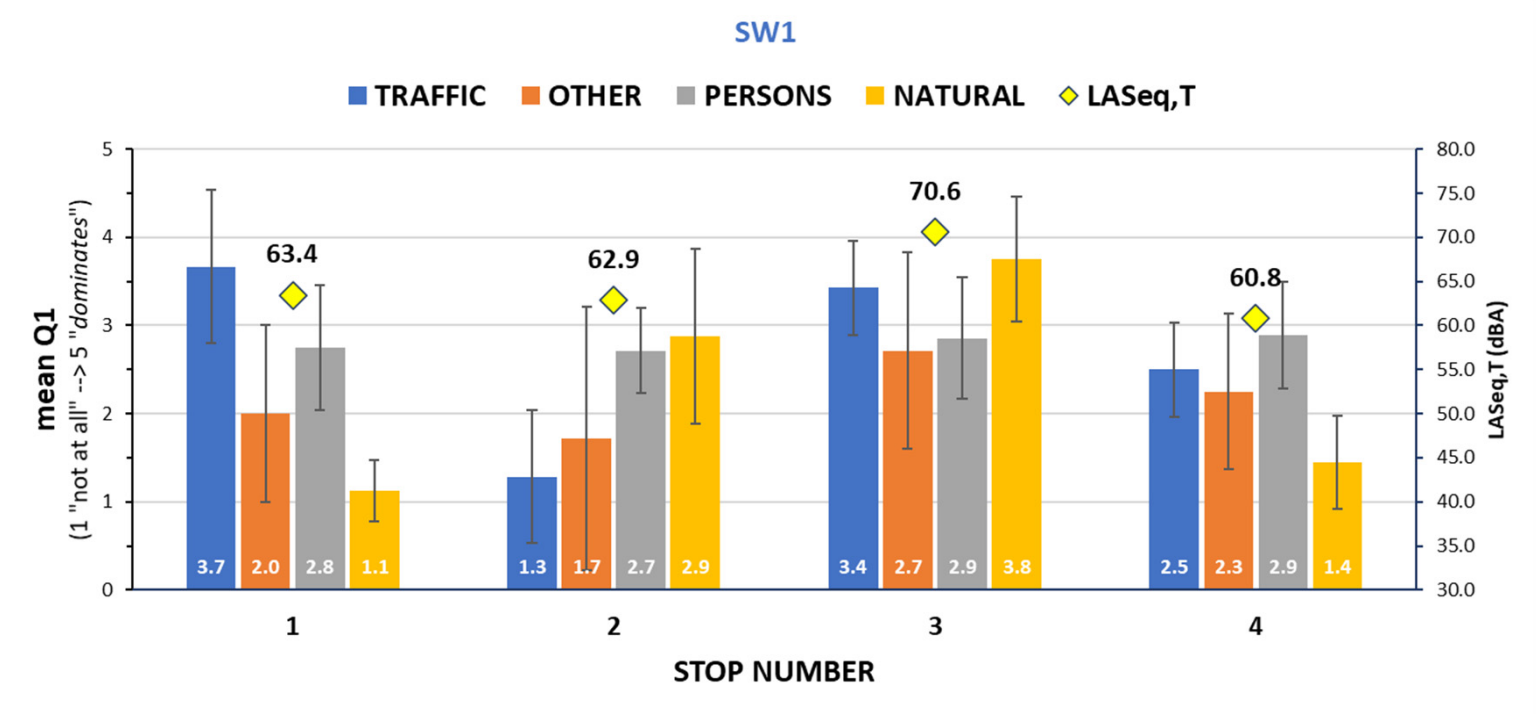

Figure 12. Sound source identification during Soundwalk 1 (SW1). Mean answers with standard deviations as error bars, and the noise equivalent levels at each evaluation site.

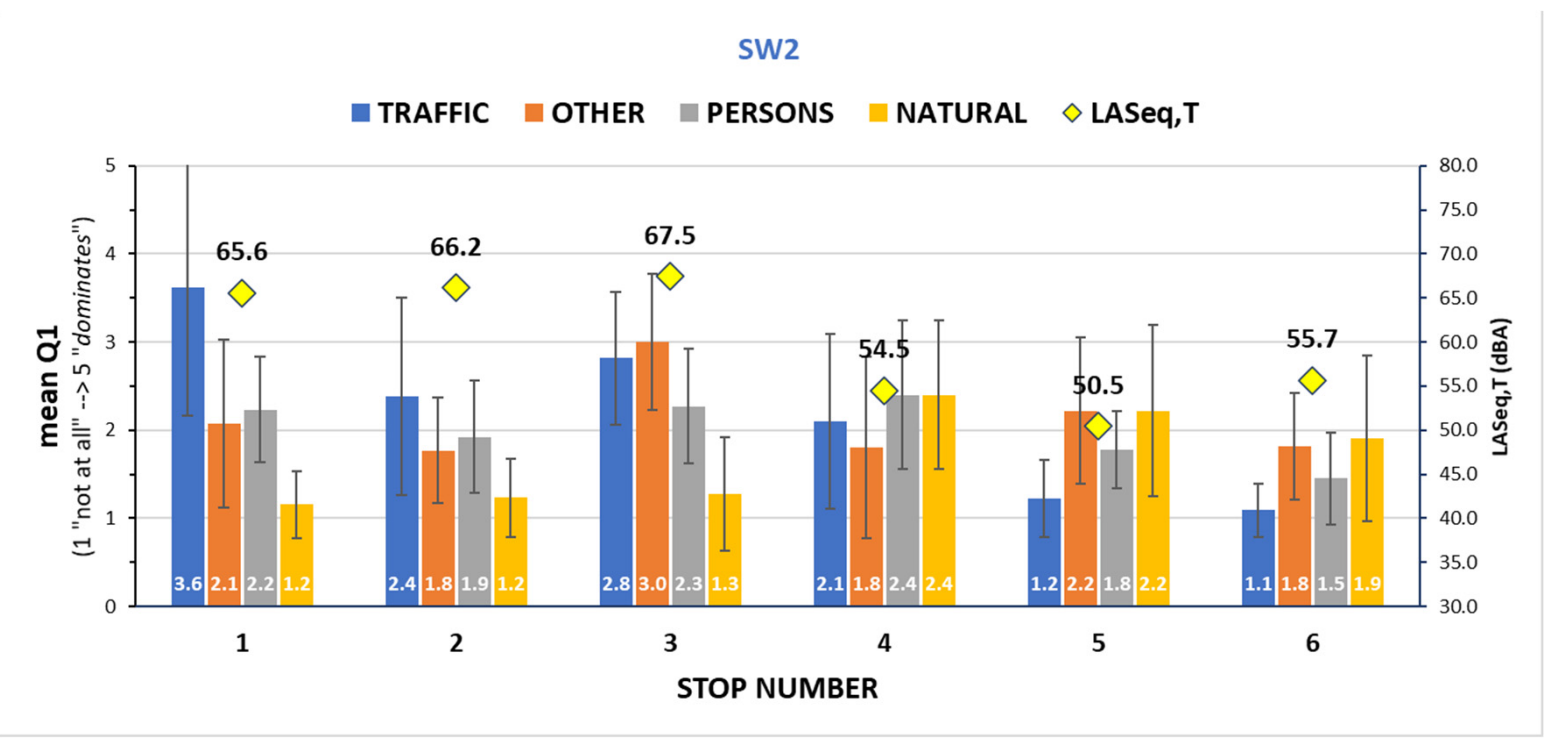

Figure 13. Sound source identification during Soundwalk 2 (SW2). Mean answers with standard deviations as error bars, and noise equivalent levels at each evaluation site. 


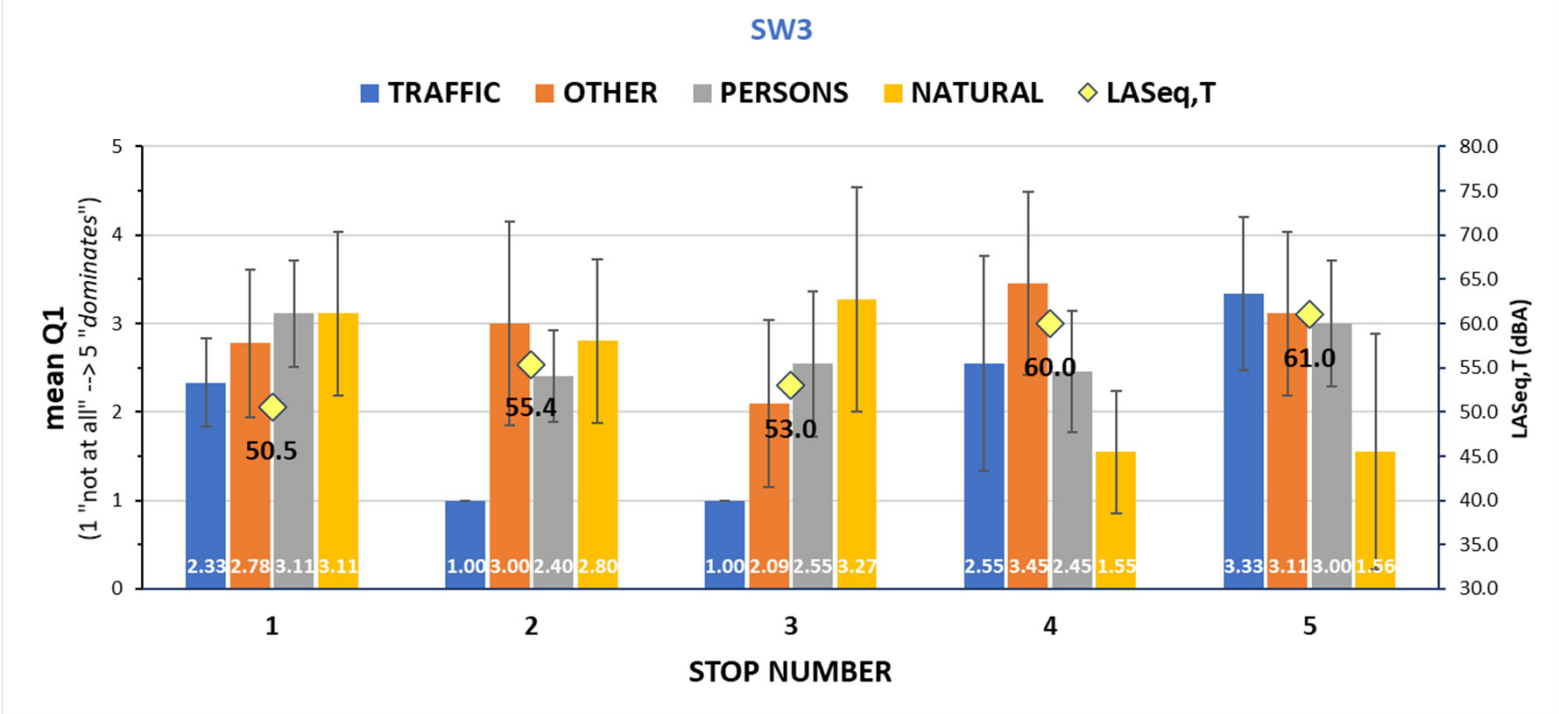

Figure 14. Sound source identification during Soundwalk 3 (SW3). Mean answers with standard deviations as error bars, and noise equivalent levels at each evaluation site.

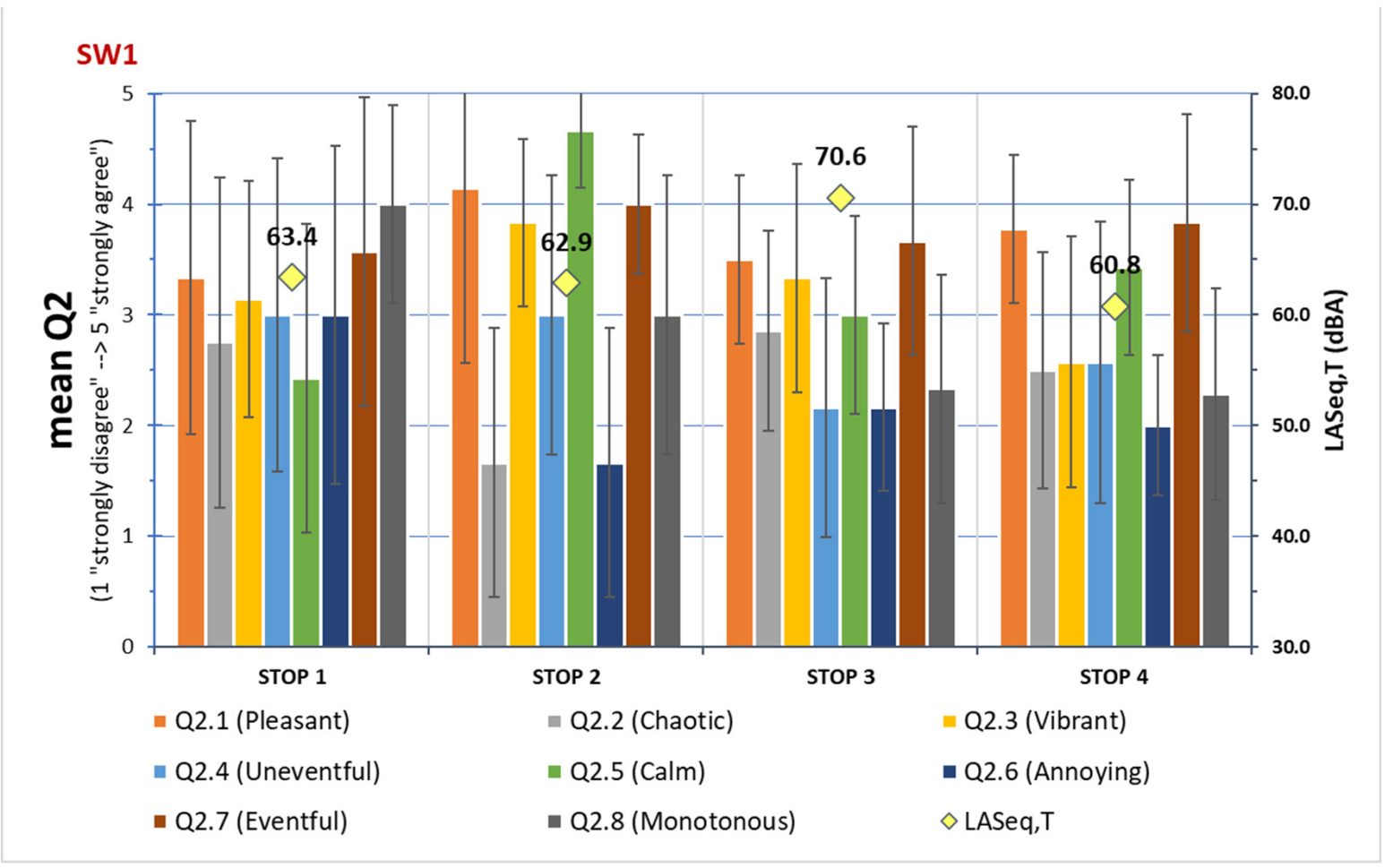

Figure 15. Perceived affective quality during Soundwalk 1 (SW1). Mean answers with standard deviations as error bars, and noise equivalent levels at each evaluation site. 


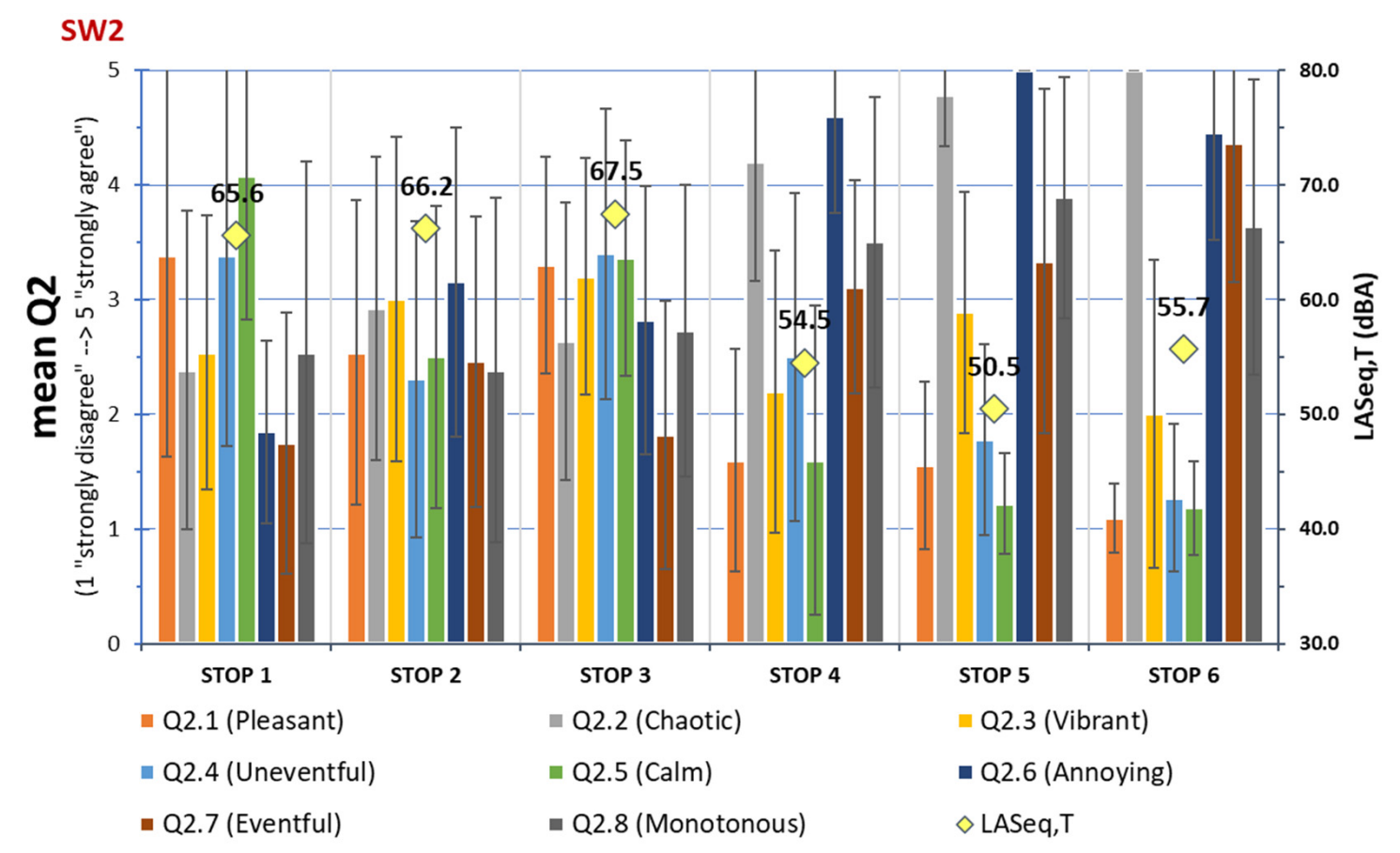

Figure 16. Perceived affective quality during Soundwalk 2 (SW2). Mean answers with standard deviations as error bars, and noise equivalent levels at each evaluation site.

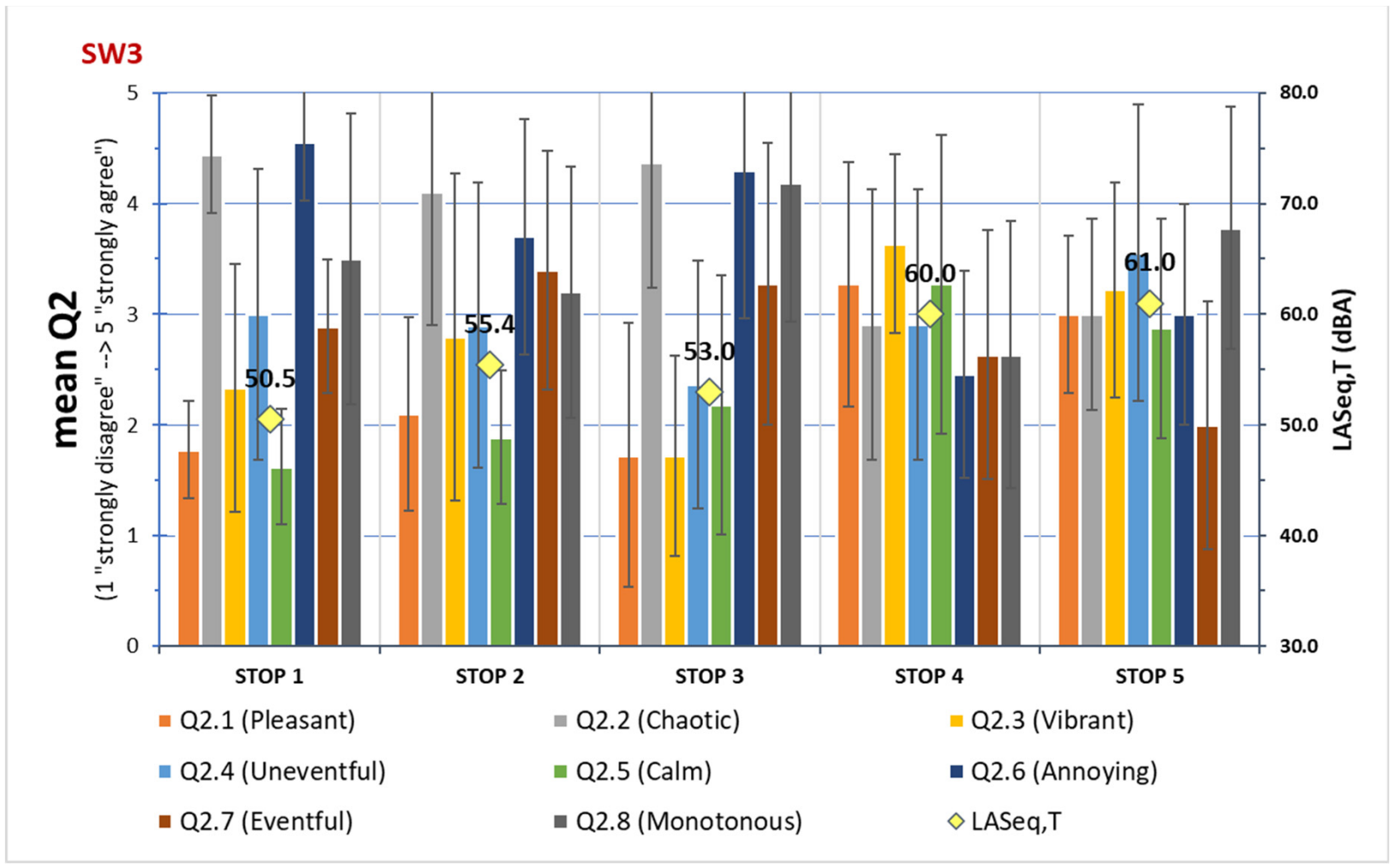

Figure 17. Perceived affective quality during Soundwalk 3 (SW3). Mean answers with standard deviations as error bars, and noise equivalent levels at each evaluation site. 


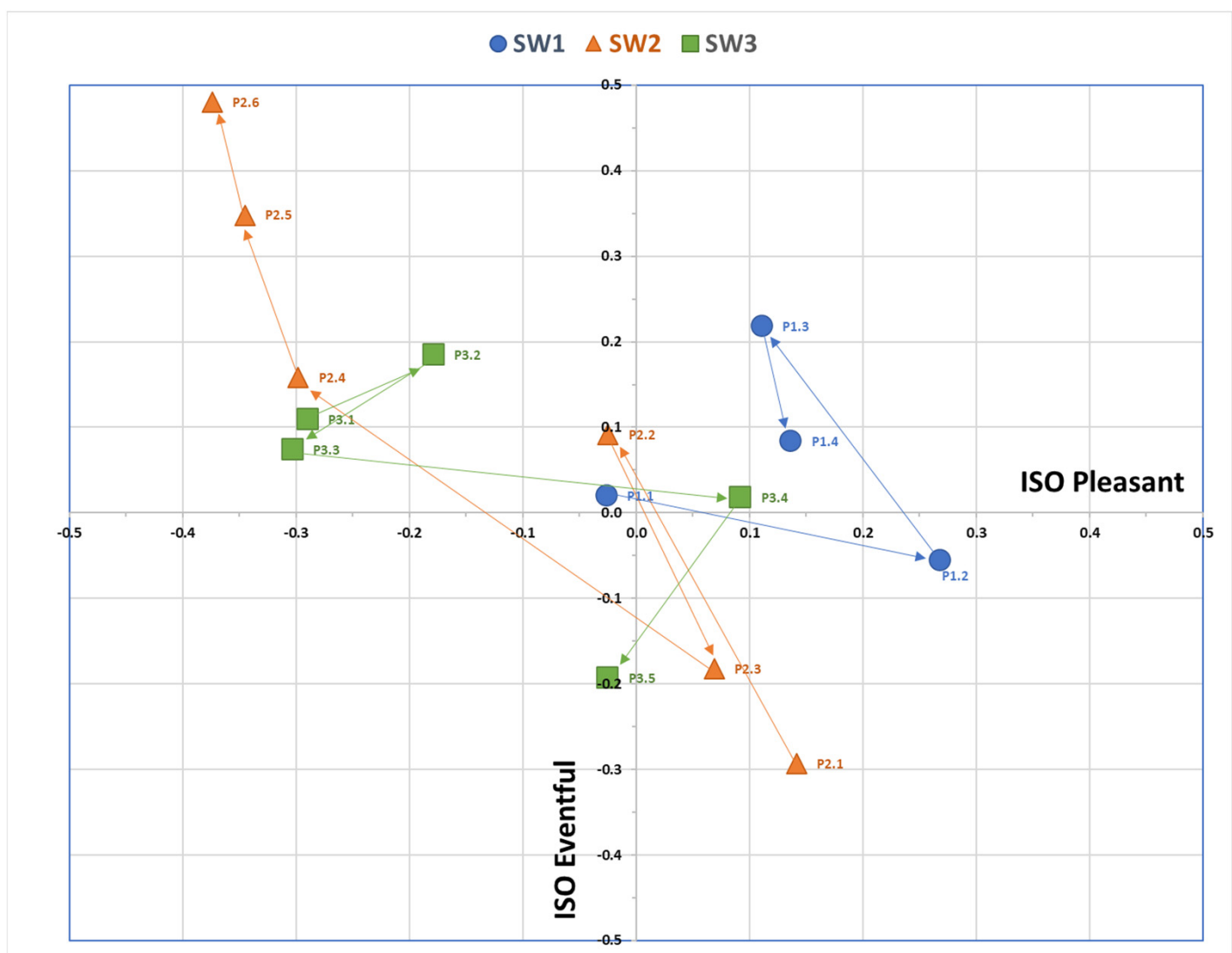

Figure 18. Pleasantness (P) and Eventfulness (E), as derived from ISO 12913-3 formulae and Q2 data, at every stop on the path during SW1, SW2, and SW3-the arrows indicate the sequences of stops during the soundwalks.

\subsubsection{Assessment of the Surrounding Sound Environment}

The assessment of the surrounding sound environment was initially carried out during the first soundwalk by Q3 (overall soundscape appraisal), Q4 (environmental sound appropriateness), Q5 (environmental sound calmness), Q6 (environmental sound pleasantness), and Q7 (environmental sound loudness). However, as previously explained, Q5 and Q6 were eliminated from the questionnaire used in the second and third soundwalks. Thus, only Q3, Q4, and Q7 have been shared along the three soundwalks carried out to date. Figures 19-21 show the mean answers to these questions, together with the noise descriptor information. Standard deviations relative to the means are also shown as side-by-side pictures so that the figures can be better seen and interpreted.

\subsection{Comparison between Visually Impaired Sample and Nonvisually Impaired Samples}

After the three soundwalks with the visually impaired groups were conducted, it was decided to attempt an asynchronous comparison with a normally sighted group, since the soundscape data were available for both groups at a specific location: the Mirador San Nicolás, which was covered by both the SSID campaign in 2019 [11] and the ONCE campaign in 2020 (i.e., Stop 1 in SW3). The two datasets were quite different, in terms of both the sample size (i.e., $\mathrm{N}=33$ for the nonvisually impaired of SSID; $\mathrm{N}=9$ for the visually impaired of ONCE), and the contexts where the perceptual data was gathered, in terms of the acoustic environment. Nevertheless, this was considered as a viable approach to explore the trends of the perception differences between groups.

Figure 22 shows that, when looking at the "positive" attributes of the soundscape circumplex model [18], the visually impaired sample always had lower scores than the nonvisually impaired group. The Pleasantness, Calmness, and Eventfulness mean scores 
for the visually impaired group were lower than for those of the nonvisually impaired. Conversely, when looking at the "negative" region of the soundscape circumplex model, the attributes were scored higher by the visually impaired group. The mean scores for the attributes, Chaotic, Annoying, and Monotonous, were higher for the visually impaired group than for the nonvisually impaired group.
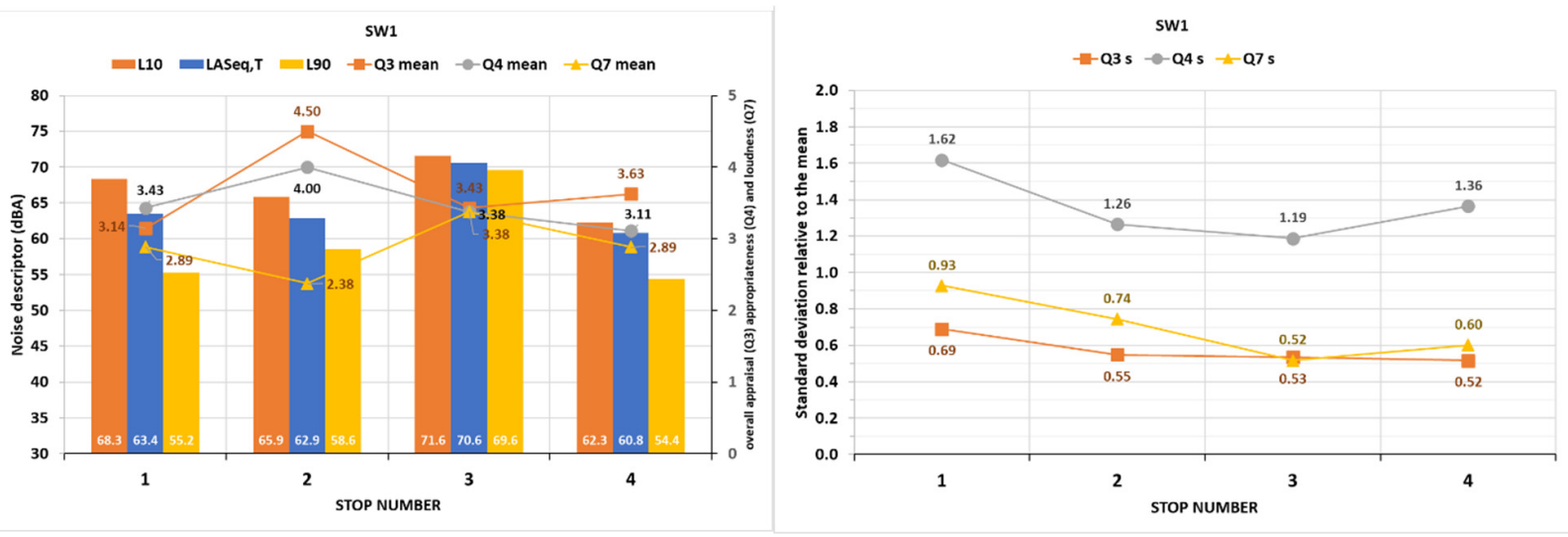

Figure 19. Mean answers to Q3 (overall appraisal), Q4 (appropriateness), and Q7 (loudness), together with environmental noise descriptor information: (left) standard deviations around the means for these answers at each stop site; and (right) during the first soundwalk (SW1).
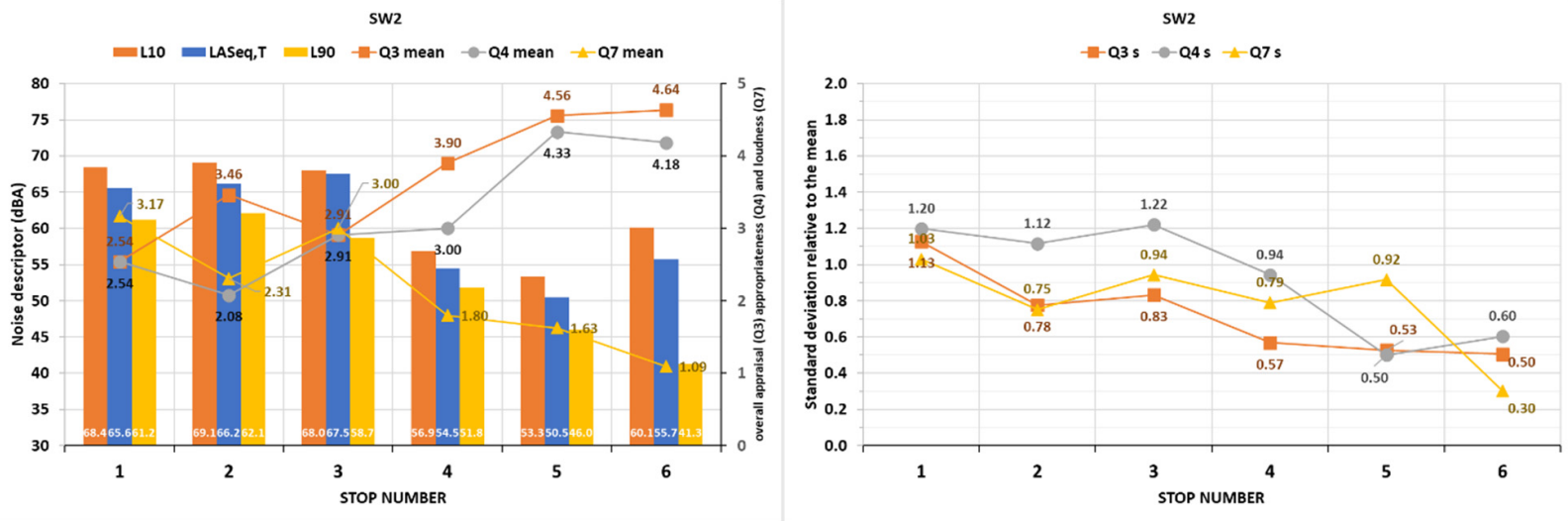

Figure 20. Mean answers to Q3 (overall appraisal), Q4 (appropriateness), and Q7 (loudness), together with environmental noise descriptor information: (left) standard deviations around the means for these answers at each stop site; and (right) during the second soundwalk (SW2).
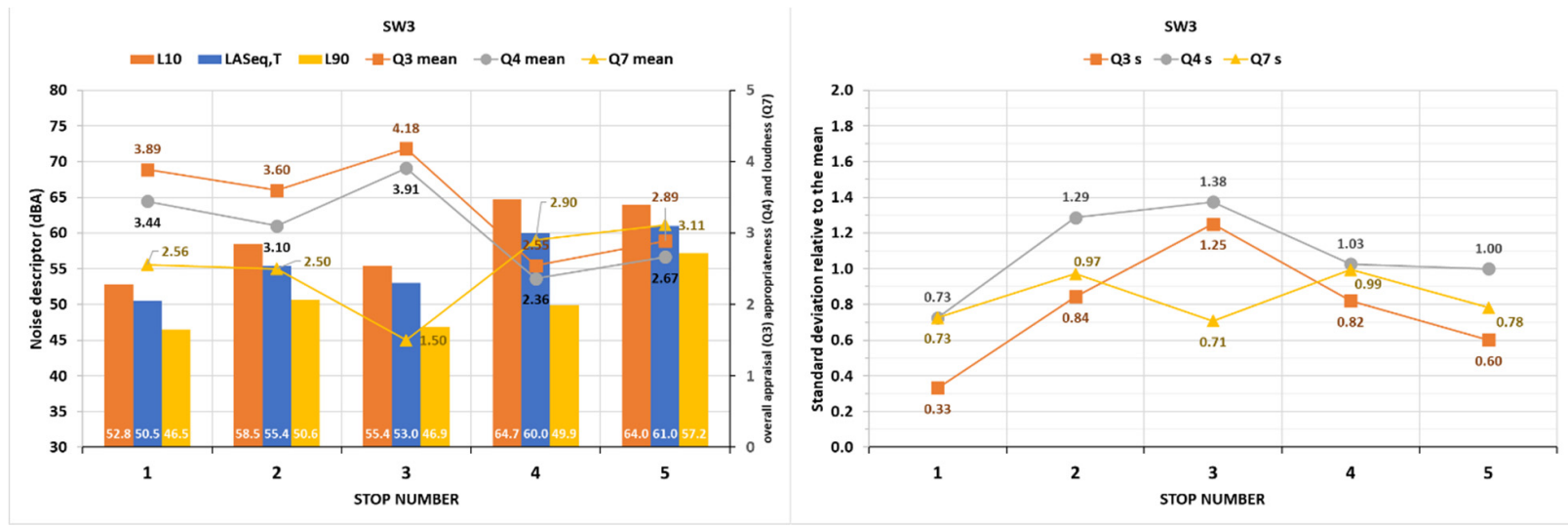

Figure 21. Mean answers to Q3 (overall appraisal), Q4 (appropriateness), and Q7 (loudness), together with environmental noise descriptor information: (left) standard deviations around the means for these answers at each stop site; and (right) during the third soundwalk (SW3). 


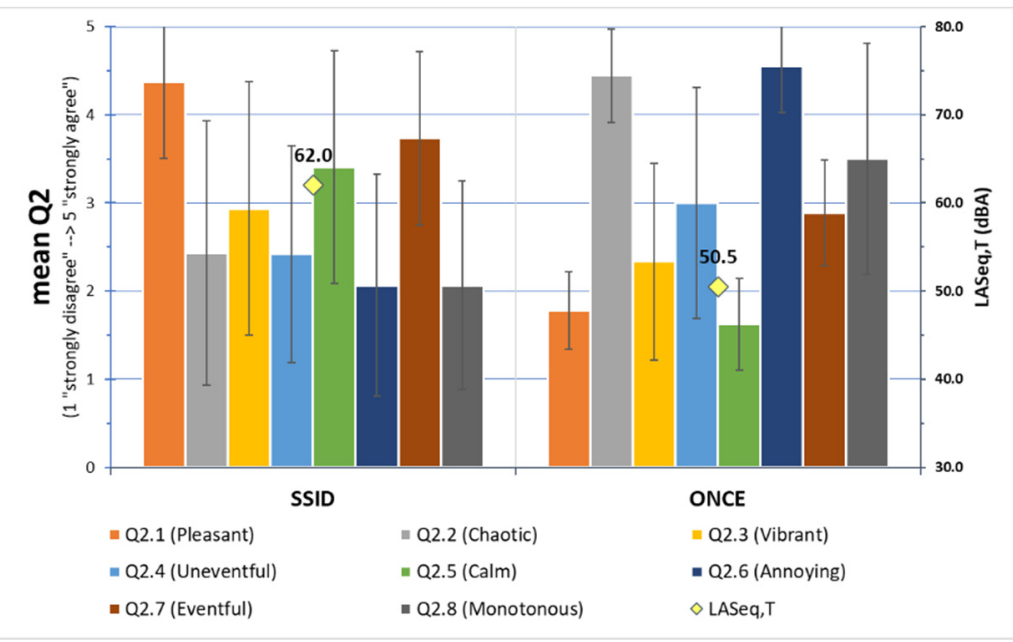

Figure 22. Mean score comparison of the eight perceptual attributes, at the Mirador San Nicolas viewpoint, SSID (nonvisually impaired) (2019), and ONCE (visually impaired) (2020) evaluations. Standard deviations as error bars, and noise equivalent levels as in Figures 14-16.

In terms of the actual acoustic environment, Table 8 shows that the environmental indices were quite different between the two campaigns, with data in 2020 showing considerably lower noise levels. A lot of people were around in 2019, with tourists, residents, and some street vendors composing a kind of folk festive atmosphere, resulting in higher sound levels. Contrarily, and because of the time of the day, in 2020, there were few people around, mostly maintenance workers (for house gardens and street reparations) that led to a much quieter scenario at Mirador San Nicolas. This mismatch between the objective and subjective data highlights that the changes in the acoustic environment (i.e., reduction in the sound levels), for visually impaired people, did not lead to the variation in perceptual outcomes that one would expect, namely, the soundscape being more pleasant and less chaotic.

Table 8. Comparison of sound levels in $\mathrm{dB}(\mathrm{A})$ for the 2019 (SSID) and 2020 (ONCE) data collection campaigns.

\begin{tabular}{ccccccccc}
\hline San Nicolás Viewpoint & LCeq $^{(\mathbf{1})}$ & LAeq & LAF10 & LAFmax & LAF90 & LAFmin & LAF10-LAF90 & LAE \\
\hline SSID (2019) & 67.3 & 62.0 & 64.2 & 78.2 & 56.7 & 52.0 & 7.5 & 87.6 \\
ONCE (2020) & 62.3 & 50.5 & 52.8 & 54.7 & 46.5 & 45.2 & 6.3 & 68.3 \\
\hline
\end{tabular}

(1) LCeq dB(C).

\section{Discussion}

\subsection{Methodological Issues and Protocol Revision}

After the first soundwalk was conducted, it was discovered that the online surveys must be adapted to electronic devices for optimal performance with visually impaired people. The adaptation should include less questionnaire pages, and easier marking boxes, or sliders, to move around the questionnaire itself, just to mention two important changes, which only a specific design by specialists could accomplish. Without the time or financial support to do so, after the first soundwalk was completed, the decision was made to share with the participants both versions of the questionnaire, an optimized online version, and a paper version that a nonvisually impaired assistant would fill in. In successive soundwalks after the first, it was also learned that new questions should be added to the questionnaire in order to include survey information on some urban soundscape nuances that are relevant to people with limited vision, or to add unique insights not foreseen by the nonlimited.

\subsection{Soundscape Evaluations of Visually Impaired People}

Previous perception studies, conducted by means of soundwalks in Granada, showed an overall greater agreement (lower $\sigma$ ) in the survey answers assessing traffic-sound-source 
identification $[7,8]$. From this analysis, it seems that traffic, as a noise source in the city, affects visually impaired people to a greater extent than it does nonvisually impaired people, this being the main reason for the dispersion of the results around the mean as the traffic influence increases. The effect of water is noticeable when comparing the evaluations at Stop 3 during SW1 (water falling), versus the coincident Stop 1 during SW2 (dry fountain). All but traffic noise sources are attributed a stronger influence during SW1 than in SW2. It seems as if noise from water falling —environmental equivalent, level $5 \mathrm{dBA}$ or higher during SW1-does not influence the overall assessment of noise from traffic, and this was similar in both cases; however, it does affect the degree of agreement, which was lower during SW2 (higher $\sigma$ ). Contrarily, noise from water does influence agreement when assessing the other three sound sources, these being answer values spread out over a similar and smaller range (lower $\sigma$ ) in SW2.

Lower environmental noise levels seem to have contributed to the increase in the influence of natural sound sources in the evaluations during SW2 and SW3. Except for the case already mentioned (SW1 Site 3, coincident with SW2 Site 1), it is also noticeable that when the noise from the traffic was reduced, other noise sources gained relevance, especially sounds from people and nature. This was especially relevant during SW3, along the Albaicín Moorish district soundwalk, which experienced little or no traffic at all, until Stop Site 5 was reached. SW3 Stop 5 is coincident with SW1 Stop 4, the final stop in both soundwalks, at a big square dominated by noise from people walking around and limited traffic driving nearby. The greater influence of noise from traffic at this site, compared to the rest of the evaluation sites in both soundwalks, turns out in a lower degree of agreement (higher $\sigma$ ), a similar result as at SW2 Stop 1, mentioned previously.

Soundwalk 1 , conducted without previous knowledge of the participants' attitudes towards the research methodology, or the previous knowledge of the researchers about the visually impaired collective, shows a similar pattern in Stops 1,3, and 4, dominated by traffic noise and great human activity, and a much more pleasant and calmed assessment at Site 2, characterized by being at a certain distance from the main street, with intense traffic flow but hidden from the circulation of vehicles. Soundwalk 2, conducted along the historical part of the city center, shows a transition from the first three stops, assessed as mostly calm and pleasant, to the more chaotic and annoying stops, 4, 5, and 6 . The answers at Stop 6 are surprising, as this site is characterized by no vehicle circulation, few humans walking around, and mostly natural (birds) sound sources at any time of the day. As this soundwalk was the longest of the three, tiredness and a lack of attention may have influenced this final stop evaluation. The Soundwalk 3 answers are also surprising, as this evaluation took place along a path traversing the Albaicín Moorish district, characterized by little or restricted traffic, people walking around, and easily noticeable natural sounds. Figure 17 shows a transition from mostly annoying and chaotic ambiences at Sites 1 to 3 , to calmer and more pleasant ambiences at Sites 4 and 5. As maintenance works were ongoing at the time that the soundwalk was carried out, consisting of cleaning, vegetation arrangement, the tidying up of flowers and trees, and street mechanical dust blowing for cleaning purposes, it seems as if these sounds were interpreted as mostly disturbing and annoying for the visually impaired. Once the city center was reached, at Stops 4 and 5, the participants mostly interpreted the acoustic ambience as familiar and, consequently, more pleasant and calm to their own usual feelings. These results indicate a clear interpretive difference between visually impaired and nonvisually impaired people, and the importance of the acoustic ambience for visually impaired people to orientating themselves, walking around, and enjoying the environment.

Overall sound quality (Q3) and appropriateness (Q4) follow a similar pattern, increasing with lower environmental levels, just as the previous assessments by nonvisually impaired people had already shown in Granada [8]. However, this overall behavior also shows some noticeable differences at some emblematic sites. That is the case during the first soundwalk at Stop 3, with a similar assessment as that at Stop 1, although with much higher environmental levels. It is also the case during the second soundwalk, at Stops 1, 2, 
and 3, the three sites characterized by similar environmental levels but with high contrasts in the answers to Q3 and Q4 at Stop Site 2 with respect to 1 and 3. Moreover, it is also the case during the third soundwalk at Stop Site 3, where the environmental levels, similar to those at Site 1, are perceived as much better and appropriated. Stop 3 during SW1 is the Plaza Isabel la Católica, an emblematic site in the city center, with a fountain with water that day; Stop 2 during SW2 is a small square where students from a nearby school get out for midday rest; and Stop 3 during SW3 is a really beautiful and peaceful mirador in the Albaicín Moorish district, with limited access to people and no traffic compared to Stop 1 and, consequently, further away from noises originating from outside of the place. These exceptions to the Q3-Q4 answers from the visually impaired people, with respect to the nonimpaired people, may be pointing out the special importance of the environmental levels for this collective. As they are familiar with the site they are evaluating, this would indicate that, rather than the environmental levels, it is the presence (or absence) of certain noises that highly affects their perceptions of the overall quality and appropriateness. If we look at the right graphs in Figures 18-20, it can also be seen that the answers to Q3 (overall quality) produce a larger match, a lower standard deviation, than those to Q4 (appropriateness), higher values for the $\sigma$. The coincidences around the mean for the answers to Q7 show high coincidence and common criteria, in order to evaluate the loudness at the evaluation sites.

\subsection{Differences in Perceptual Outcomes between Visually Impaired and Nonvisually Impaired People}

As shown in Figure 22, the SSID session, conducted with nonvisually impaired people, was rated as significantly more pleasant and less chaotic than the ONCE session with visually impaired people. Given the differences in the acoustic environments and contexts between the two sessions, it is difficult to draw direct conclusions about the differences in the perceptions between the two groups. However, on the basis of the acoustic metrics provided in Table 8 , it can be seen that the ONCE session was substantially quieter $(-11.5 \mathrm{dBA})$, with a smaller difference between the foreground and background sound levels $\left(-1.2 \mathrm{~dB} \mathrm{~L}_{\mathrm{A} 10}-\mathrm{L}_{\mathrm{A} 90}\right)$. Given this decrease in the sound level, and the lower amount of variation in the sound level, we would, therefore, likely expect the soundscape to be perceived as more pleasant and less chaotic. This expectation is contradicted by the responses given in the ONCE session, indicating that there is some difference in the perceptions between the two groups, which may not be explained by the differences in the acoustic environment. What drives this difference in the perceptions, at what thresholds it may appear, and how the contexts of the locations and sound sources affect this difference, will need to be investigated in future research, perhaps making use of the methodological suggestions developed in this study.

The results are indeed difficult to interpret: the soundscape attributes in the "negative" region of the circumplex model were scored higher by the visually impaired group, in spite of the relatively lower sound levels they were exposed to at Mirador San Nicolas in 2020. With some speculation, one could imagine that the visually impaired participants have a rather different understanding of the whole soundscape pleasantness-annoyance continuum. A possible explanation, based on the feedback gathered informally from the soundwalk participants after the soundwalk sessions, is that visually impaired people often feel more comfortable in loud environments. Such a trend could also be observed in the SW3 results, when moving from San Nicolas to Plaza Nueva: in Figure 18, where the path evolves to more pleasant soundscapes, and, in Table 8 and Figure 22, where a louder environment results in more positive assessments of the soundscapes. This finding may be supported by other research in soundscape studies addressing the concept of "audible safety", where sound sources that are commonly considered to be negative or unpleasant (e.g., traffic noise) may be indicators of "safety", i.e., things and sound events happen as expected and there is no immediate threat that could result in sudden changes (unlike with sudden silence) in the acoustic environments [20,21]. For visually impaired people, who rely mostly on auditory information to get environmental and situational awareness, this 
aspect might be particularly crucial. Overall, these findings support the idea that different groups with different sensory profiles are likely to have different perceptual thresholds when it comes to assessing soundscape pleasantness or annoyance in context.

\section{Conclusions}

An urban soundscape assessment of the Granada city center was conducted with the collaboration of visually impaired citizens, an evaluation that complements previous studies in other places of the city that did not include people with limited vision. An adapted version of a standardized questionnaire was presented to participants along three soundwalks carried out in September 2020, right after the COVID-19 lockdown ended and almost-normal activity had resumed in Granada. The lessons learnt in the soundscape research with the participation of this community, including the difficulties, the adaptation of previous methods and procedures, and the new findings and perspectives arising from the first results, are presented in this work.

When it comes to people with visual impairments, new questions emerge for architects and urban sound practitioners, since the current normative values are currently optimized to target only people with "normal" visual abilities [22]. Acknowledging "aural diversity", i.e., the idea that everyone listens differently [23] and perceives sound differently [24], means working towards more inclusive communities and, consequently, more sustainable cities. Th results from this case study will, hopefully, guide future research on inclusive soundscape evaluations.

Supplementary Materials: The following are available online at https:/ / www.mdpi.com/article/10.3 390/su132413867/s1.

Author Contributions: The authors confirm the following contributions to the paper: conceptualization and design, J.V., J.A.A., R.G.-Q., F.A., T.O., A.M. and J.K.; methodology, J.V., J.A.A., R.G.-Q., F.A., T.O., A.M. and J.K.; field campaign, J.V., J.A.A., R.G.-Q. and F.A.; data preparation, J.V., J.A.A., F.A., T.O. and A.M.; analysis and interpretation of results, J.V., J.A.A., R.G.-Q., F.A., T.O., A.M. and J.K.; writing—original draft preparation, J.V. and F.A.; writing—review and editing, J.V., J.A.A., R.G.-Q., F.A., T.O., A.M. and J.K.; project administration, J.V. and J.K. All authors have read and agreed to the published version of the manuscript.

Funding: The University of Granada team received no external funding for this project. The UCL team was funded through the European Research Council (ERC) Advanced Grant (no. 740696) on "Soundscape Indices" (SSID).

Institutional Review Board Statement: The study was conducted according to the guidelines of the Declaration of Helsinki, and approved by the Research Ethics Commission of the University of Granada (Approval Code: 808/CEIH/2019; Approval Date: 22 March 2019).

Informed Consent Statement: Informed consent was obtained from all subjects involved in the study.

Data Availability Statement: The experimental data used to support the findings of this study are available from the corresponding author upon request.

Acknowledgments: The authors are grateful to the ONCE delegates in Granada, and to Granada City Council political representatives for their support and help. The authors would also like to express their gratitude to the ONCE affiliates who took part in the soundwalks. Instrumentation from the University of Granada anechoic facility is also highly appreciated.

Conflicts of Interest: The authors declare no conflict of interest.

\section{References}

1. Welsh Government. Noise and Soundscape Action Plan 2018-2023; Ministry of Environment: Cardiff, UK, 2018.

2. Kang, J.; Aletta, F.; Gjestland, T.T.; Brown, L.A.; Botteldooren, D.; Schulte-Fortkamp, B.; Lercher, P.; van Kamp, I.; Genuit, K.; Fiebig, A.; et al. Ten questions on the soundscapes of the built environment. Build. Environ. 2016, 108, 284-294. [CrossRef]

3. European Environment Agency. Environmental Noise in Europe-2020; Publications Office of the European Union: Luxembourg, 2020. [CrossRef] 
4. Radicchi, A.; Yelmi, P.C.; Chung, A.; Jordan, P.; Stewart, S.; Tsaligopoulos, A.; McCunn, L.; Grant, M. Sound and the healthy city. Cities Health 2021, 5, 1-13. [CrossRef]

5. Margaritis, E.; Kang, J.; Aletta, F.; Axelsson, Ö. On the relationship between land use and sound sources in the urban environment. J. Urban Des. 2020, 25, 629-645. [CrossRef]

6. Aletta, F.; De Coensel, B.; Lindborg, P. Editorial: Human Perception of Environmental Sounds. Front. Psychol. 2021, 12, 714591. [CrossRef] [PubMed]

7. Almagro Pastor, J.A.; Vida Manzano, J.; García Quesada, R. Soundscape approach for noise management of conflict urban areas. The PTS case in Granada (Spain). In Proceedings of the Internoise 2019 Conference, Madrid, Spain, 16-19 June 2019; Institute of Noise Control Engineering: Madrid, Spain, 2019.

8. Vida, J.; Pastor, J.A.A.; Quesada, R.G. The importance of changing urban scenery in the assessment of citizens' soundscape perception. On the need for different time-related points of view. Noise Mapp. 2021, 8, 138-161. [CrossRef]

9. Vida, J.; Pastor, J.A.A.; Quesada, R.G.; Aletta, F.; Oberman, T.; Mitchell, A.; Kang, J. The "sound of silence" in Granada during the COVID-19 lockdown. Noise Mapp. 2021, 8, 16-31. [CrossRef]

10. Radicchi, A.; Vida Manzano, J. Soundscape evaluation of urban social spaces. A comparative study: Berlin-Granada. J. Acoust. Soc. 2018, 144, 1660. [CrossRef]

11. Mitchell, A.; Oberman, T.; Aletta, F.; Erfanian, M.; Kachlicka, M.; Lionello, M.; Kang, J. The Soundscape Indices (SSID) Protocol: A Method for Urban Soundscape Surveys-Questionnaires with Acoustical and Contextual Information. Appl. Sci. 2020, 10, 2397. [CrossRef]

12. Mediastika, C.E.; Sudarsono, A.S.; Kristanto, L.; Tanuwidjaja, G.; Sunaryo, R.G.; Damayanti, R. Appraising the sonic environment of urban parks using the soundscape dimension of visually impaired people. Int. J. Urban Sci. 2020, 24, 216-241. [CrossRef]

13. International Organization for Standardization. ISO/TS 12913-2:2018 Acoustics—Soundscape—Part 2: Data Collection and Reporting Requirements; ISO: Geneva, Switzerland, 2018.

14. Mediastika, C.E.; Sudarsono, A.S.; Kristanto, L. Indonesian shopping malls: A soundscape appraisal by sighted and visually impaired people. Arch. Eng. Des. Manag. 2020, 1-20. [CrossRef]

15. International Organization for Standardization. ISO 12913-1:2014 Acoustics-Soundscape-Part 1: Definition and Conceptual Framework; ISO: Geneva, Switzerland, 2014.

16. Ayuntamiento de Granada. Noticias Destacada. Retrieved 27 October 2021. 2020. Available online: https://www.granada. org/inet/wprensa.nsf/a9bdd07842ba9975c125784d002ecdc5/dfd785008ff1ad7bc12585dc004362da!OpenDocument (accessed on 10 December 2021).

17. Aletta, F.; Oberman, T.; Axelsson, Ö.; Xie, H.; Zhang, Y.; Lau, S.K.; Tang, S.K.; Jambrošić, K.; De Coensel, B.; van den Bosch, K.; et al. Soundscape assessment: Towards a validated translation of perceptual attributes in different languages. In Proceedings of the Internoise 2020 Conference, Seoul, Korea, 5-8 August 2020.

18. Axelsson, Ö.; Nilsson, M.; Berglund, B. A principal components model of soundscape perception. J. Acoust. Soc. Am. 2010, 128, 2836-2846. [CrossRef] [PubMed]

19. International Organization for Standardization. ISO/TS 12913-3:2019 Acoustics—Soundscape—Part 3: Data Analysis; ISO: Geneva, Switzerland, 2019.

20. van den Bosch, K.A. Safe and Sound: Soundscape Research in Special Needs Care; University of Groningen: Groningen, The Netherlands, 2015.

21. Sayin, E.; Krishna, A.; Ardelet, C.; Decré, G.B.; Goudey, A. "Sound and safe": The effect of ambient sound on the perceived safety of public spaces. Int. J. Res. Mark. 2015, 32, 343-353. [CrossRef]

22. Rychatáriková, M.; Herssens, J.; Heylighen, A. Towards more inclusive approaches in soundscape research. In Proceedings of the International Congress and Exposition on Noise Control Engineering, New York, NY, USA, 19-22 August 2012.

23. Aural Diversity Network. Home. Retrieved 27 October 2021, from Aural DIversity Project. 2021. Available online: https:/ /auraldiversity. org/index.html (accessed on 10 December 2021).

24. Erfanian, M.; Mitchell, A.; Aletta, F.; Kang, J. Psychological well-being and demographic factors can mediate soundscape pleasantness and eventfulness: A large sample study. J. Environ. Psychol. 2021, 77, 101660. [CrossRef] 